February 2000 - NREL/TP-570-27592

\title{
Small Modular Biopower Initiative Phase I Feasibility Studies Executive Summaries
}

R. Bain

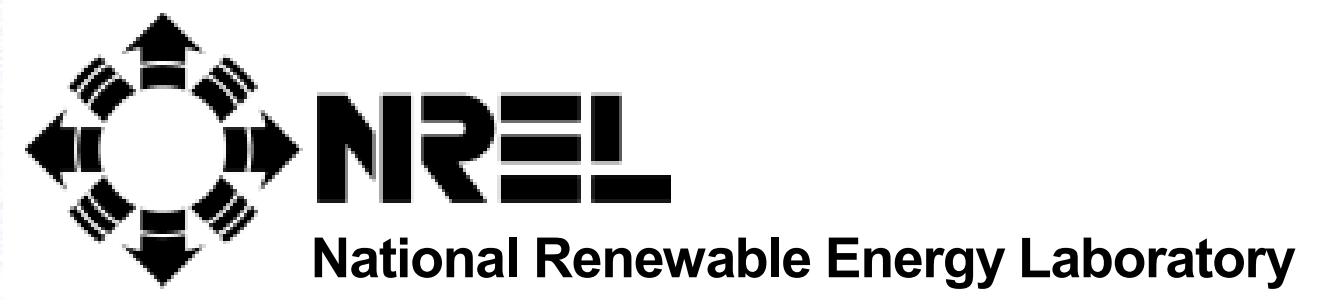

1617 Cole Boulevard

Golden, Colorado 80401-3393

NREL is a U.S. Department of Energy Laboratory

Operated by Midwest Research Institute $\bullet$ Battelle $\bullet$ Bechtel

Contract No. DE-AC36-99-G010337 
February 2000 - NREL/TP-570-27592

\section{Small Modular Biopower Initiative Phase I Feasibility Studies Executive Summaries}

\section{R. Bain}

NREL and Sandia jointly managed procurement and monitored technical progress and oversight for the contracts. This report prepared under Task No. BP001040

1617 Cole Boulevard

Golden, Colorado 80401-3393

NREL is a U.S. Department of Energy Laboratory

Operated by Midwest Research Institute $\bullet$ Battelle $\bullet$ Bechtel

Contract No. DE-AC36-99-G010337 


\section{NOTICE}

This report was prepared as an account of work sponsored by an agency of the United States government. Neither the United States government nor any agency thereof, nor any of their employees, makes any warranty, express or implied, or assumes any legal liability or responsibility for the accuracy, completeness, or usefulness of any information, apparatus, product, or process disclosed, or represents that its use would not infringe privately owned rights. Reference herein to any specific commercial product, process, or service by trade name, trademark, manufacturer, or otherwise does not necessarily constitute or imply its endorsement, recommendation, or favoring by the United States government or any agency thereof. The views and opinions of authors expressed herein do not necessarily state or reflect those of the United States government or any agency thereof.

Available electronically at http://www.doe.gov/bridge

Available for a processing fee to U.S. Department of Energy

and its contractors, in paper, from:

U.S. Department of Energy

Office of Scientific and Technical Information

P.O. Box 62

Oak Ridge, TN 37831-0062

phone: 865.576.8401

fax: 865.576.5728

email: reports@adonis.osti.gov

Available for sale to the public, in paper, from:

U.S. Department of Commerce

National Technical Information Service

5285 Port Royal Road

Springfield, VA 22161

phone: 800.553.6847

fax: 703.605.6900

email: orders@ntis.fedworld.gov

online ordering: http://www.ntis.gov/ordering.htm

Printed on paper containing at least $50 \%$ wastepaper, including $20 \%$ postconsumer waste 


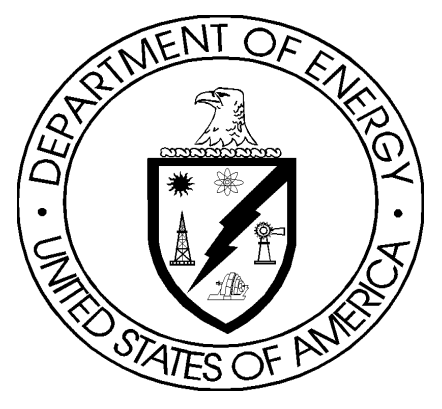

\section{SMALL MODULAR BIOPOWER INITIATIVE PHASE 1 FEASIBILITY STUDIES EXECUTIVE SUMMARIES}

November 9, 1999

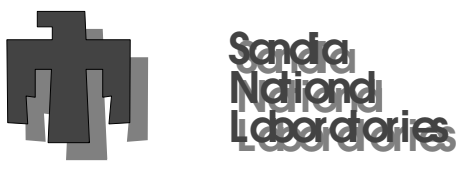




\title{
INTRODUCTION
}

In 1998, the National Renewable Energy Laboratory (NREL) in Golden, Colorado, and Sandia National Laboratories (SNL) in Albuquerque, New Mexico, placed ten cost-shared contracts to develop small modular biomass (SMB) power systems. These contracts, which compared the first phase of the Small Modular Biopower Initiative, were aimed at determining the feasibility of developing systems that are fuel-flexible, efficient, simple to operate, and whose operations have minimum negative impacts on the environment. NREL and SNL jointly managed procurement and monitored technical progress and oversight for the contracts.

The general objectives and scope of each phase of the Small Modular Biopower Initiative are described briefly:

- The Phase 1 objective is a feasibility study that includes a market assessment, resource assessment, preliminary system design, an assessment of relevant environmental and safety considerations, an evaluation of financial and cost issues, and a preliminary business plan and commercialization strategy. Each participating company will share at least $20 \%$ of the cost of the first phase.

- The Phase 2 objectives are to develop and test the performance of a prototype small-scale biopower system, to complete a detailed business plan including feedstock resource assessment, and to establish strategic partnerships with distribution/service entities. A minimum offeror cost share of $50 \%$ is required in Phases 2 and 3 of the project.

- The Phase 3 objective is to develop and demonstrate an integrated small-scale biopower system with the operation and performance required to successfully compete in the target market. This will include establishing the automated nature of feeding and operating the system, operating the system to establish operations and maintenance (O\&M) cost projections, measuring detailed emissions, and certifying the system performance. Phase 3 projects will be chosen through a limited competitive procurement process open to projects chosen for Phase 2 funding.

Small modular systems have potential applications in domestic and international markets. They have cost advantages in niche markets because of their modularity, standardized manufacture, and transport. Because they have simple connections, they will require a minimum of field engineering at customer sites. The intended power range for these systems is $5 \mathrm{~kW}$ to $5 \mathrm{MW}$.

Phase 1 of the three-phase project focused on the feasibility of developing cost-effective technologies and identifying the potential markets for each system. The feasibility studies included solutions to the following technical issues:

\author{
System capacity (as high as $5 \mathrm{MW}$ ) \\ Load following ability \\ System fuel consumption \\ Fuel flexibility \\ Number of operators and required training \\ Life cycle costs \\ Environmental impacts (feedstock-related issues; air, water, and solid emissions) \\ Safety \\ Load profile (proposed hours of operation, etc.) \\ Proposed fuel (including availability) \\ Fuel handling/feeding system and method \\ System transportability \\ Maintenance schedule and costs \\ Water consumption \\ Capability for remote monitoring (unit performance and maintenance intervals).
}


The ten contracts were placed with the following companies, listed with their corresponding technologies:

\section{Company}

Agrilectric Power, Inc.

Lake Charles, Louisiana

Bechtel National Incorporated

San Francisco, California

BIOTEN General Partnership

Knoxville, Tennessee

Carbona Corporation

Atlanta, Georgia

Community Power Corporation

Aurora, Colorado

Energy and Environmental

Research Center

Grand Forks, North Dakota

Niagara Mohawk Power Corporation

Syracuse, New York

Reflective Energies, Inc.

Mission Viejo, California

STM Corporation

Ann Arbor, Michigan

SunPower, Inc.

Athens, Ohio

\section{Technology}

Fluidized-bed combustion with steam turbine

Gasification with spark ignition engine/generator, combustion turbine, or fuel cell

Direct-fired combustion turbine

Updraft gasification with boiler/steam turbine

Gasification with spark ignition engine/generator

Fluidized-bed combustion, heat exchange fluid, steam generation, steam turbine

Gasification with spark ignition engine/generator or combustion turbine/generator

Microturbine for biogas applications

Gasification with Stirling engine/generator

Combustion with Stirling engine/generator

The ten Small Modular Biopower Initiative Phase 1 feasibility studies have been completed and executive summaries have been written to disseminate information. 


\section{Table of Contents}

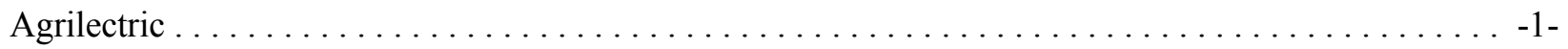

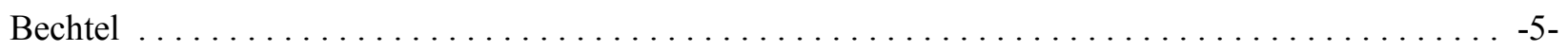

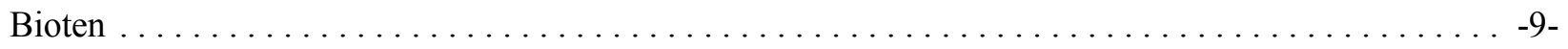

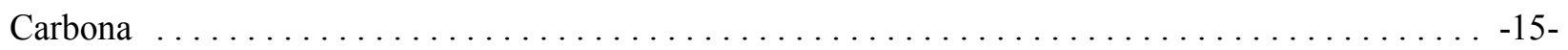

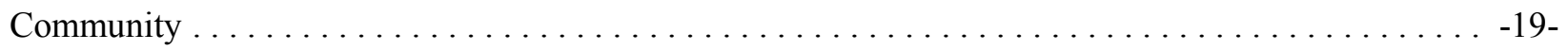

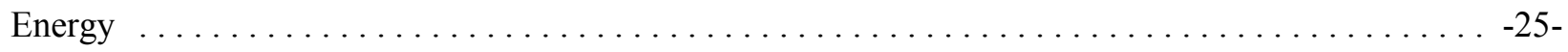

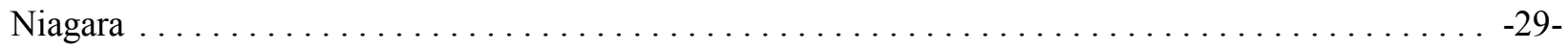

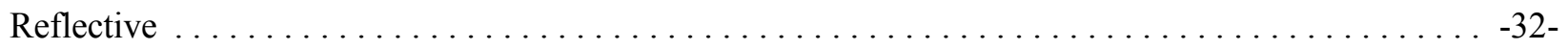

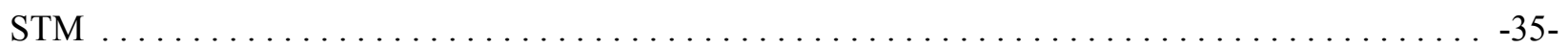

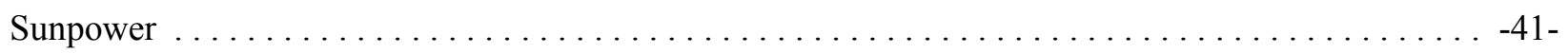




\section{Agrilectric Power, Incorporated}

Subcontractor:

Contracting Party:

Subcontract Title:

Subcontract No.:

Period of Performance:

Subcontract Contact:
Agrilectric Power, Incorporated

P.O. Box 3716

Lake Charles, LA 70602

Sandia National Laboratories

"Small Modular Biopower Project"

SNL BC-0002D

8 Jun 1999 through 30 Nov 1999

Mr. H. Charles Weiss, Tel. (318) 421-6352

\section{Introduction}

Agrilectric Power, Inc., began the project with objectives that included identifying potential markets, defining system requirements, and reviewing technical issues requiring resolution. In addition, the goals included evaluating the environmental concerns while assessing the projected costs and developing strategic partnerships required to finance and complete the business development. The technology is an extension and refinement of that used at Lake Charles, Louisiana, to generate electric power by using rice hulls as fuel with the knowledge and experience gained during the operation of the facility. The specific study involved a family of rice hull-fired power generation units (PGUs) that would be deployed in emerging markets.

By working with a Japanese manufacturer of rice milling equipment, the sizes of PGUs were identified as 500 $\mathrm{kW}, 1500 \mathrm{~kW}$, and $5000 \mathrm{~kW}$, which closely matched production of rice hulls and power requirements for the operation of three line sizes of rice milling equipment. Once these capacities were identified, the quantity of hulls produced and the power requirements for mill operations set, the actual design sizes of the generating units were known. A design for each size was made based on the PGU being sited near a rice mill of the proper size. The economics of sizes and costs of the boiler and turbine required the economic choice of steam conditions for the best combination. A review of the expected emissions projected compliance with the regulations of these types of emissions.

Price projections have been made for these units based on U.S. equipment supplies, and discussion with vendors in other countries have shown possible significant reductions of total costs. The market for these units appears to be primarily outside the United States. The protective tariffs placed on imported goods by many countries causes the equipment to be more economically viable when purchased in the country of final use. This progress of unit size identification and cost estimates for import to other countries with rice production are major advances in implementing a development strategy.

\section{Potential Markets}

The major market for this type of technology is outside the United States because of highly competitive fossil fuels, low power prices, and competing markets for rice hulls. The rice-producing areas in the United States can still dispose of rice hulls by landfilling when there is no market for the hulls such as bulk addition for animal feed. Changes in this capability that would increase the costs of disposal would increase the market potential for this technology.

Abroad, the primary rice-producing regions are Latin America, Southeast Asia, and the Pacific. Rice is also grown in parts of Egypt and Turkey, which could develop into market opportunity areas. In consideration of the current status of worldwide economies, the areas that appear to be prime, near-term market opportunities are Brazil, Uruguay, and Argentina. Asia, Thailand, India, Malaysia, Indonesia, and China are the leading countries of market potential. The Philippines are also considered a high potential but, as with most countries, economic problems still impede full development. 
The market for rice hull-fueled PGUs is thought to be small in terms of potential generation installed, but large in numbers of PGUs. The original estimate made at the beginning of the joint effort is shown in Table 1. This was based primarily in Asia.

Table 1. Original Estimate

\begin{tabular}{|l|c|c|c|}
\hline Unit Size & $500 \mathrm{~kW}$ & $1.5 \mathrm{MW}$ & $5 \mathrm{MW}$ \\
\hline Potential Number & 15 units & 8 units & 3 units \\
\hline
\end{tabular}

Table 2 lists the fuel available from a rice mill producing these hull quantities. The power consumption of the rice mill is based on the designs of the manufacturer.

Table 2. Fuel Available from Rice Mill

\begin{tabular}{|l|c|c|c|}
\hline Unit Size & $500 \mathrm{~kW}$ & $1.5 \mathrm{MW}$ & $5 \mathrm{MW}$ \\
\hline Fuel Available & 1 to $1.4 \mathrm{~T} / \mathrm{h}$ & 3 to $6 \mathrm{~T} / \mathrm{h}$ & 10 to $14 \mathrm{~T} / \mathrm{h}$ \\
\hline Total Output kWh & $480-600$ & $1400-1800$ & $4800-6000$ \\
\hline Auxiliary Use kWh & $80-100$ & $200-300$ & $800-1000$ \\
\hline Net Output kWh & $400-500$ & $1200-1500$ & $4000-5000$ \\
\hline
\end{tabular}

Based on cost estimates of U.S. supplied equipment, Table 3 indicates the expected costs for a non-site specific site. Numerous factors are involved, which at this point are assumptions only. They can directly affect the final installed cost of the generating unit.

Table 3. Expected Unit Costs

\begin{tabular}{|l|c|c|c|}
\hline Estimated Unit Cost & $500 \mathrm{~kW}$ & $1,500 \mathrm{~kW}$ & $5 \mathrm{MW}$ \\
\hline First Unit Costs & $\$ 2,985 / \mathrm{kW}$ & $\$ 2,832 / \mathrm{kW}$ & $\$ 1,750 / \mathrm{kW}$ \\
\hline Second Unit Costs & $\$ 2,835 / \mathrm{kW}$ & $\$ 2,690 / \mathrm{kW}$ & $\$ 1,663 / \mathrm{kW}$ \\
\hline
\end{tabular}

South America seems to be at least as large in potential. Further investigation in Brazil and China indicates that identifying manufacturers in countries that can produce the required equipment may reduce these costs. This does not address the concern of design confidentiality and the ability to control the release of design specifications to unauthorized parties.

\section{System Design}

The system design can burn rice hulls. Even though other fuels could be considered, the present effort is limited to the single fuel because the potential market is so large and applicable to so many areas of the world. The attached heat balance is for the $5000-\mathrm{kW}$ design and shows all major equipment. The design significance is in the boiler and combustion system. The equipment outside this area is used in many installations around the world. The steam from the boiler is transported to the steam turbine where the energy is converted from mechanical to electrical in the generator. The spent steam is condensed back into water for pumping back to the boiler. The water from the cooling tower cools the condenser. The additional capability to use low-quality steam to dry rice or a parboiling of rice operation enhances the economics of this type of technology.

The rice hulls coming from the mill are ground by a hammermill and then transported to a storage or day bin. The feeders in the bottom of the bin control the amount of hulls or fuel being fed to the burners. As the feeder discharges the hulls, hot air is combined with the hulls in a venturi type device and transported to the burners. Two burners of equal capacity on the front of the boiler introduce the hulls into the furnaces. Because the hulls have been reduced in size, they are immediately combusted in the furnace while in suspension. There is no floor or grate in the furnace of the boiler. All combustion takes place before any ash falls from the gas stream. 
As the ash-laden gas flows through the system, hoppers at each device collect it. As the gas passes through the superheater, air heater, and economizer, its temperature decreases. When the gas enters the baghouse or fabric filter, the temperature is sufficiently low so that it will not harm the fabric bags. The gas passes through the cloth and the ash is collected on the outsides of the bags and eventually falls into the hoppers for collection.

The ash formed by this process is a marketable product for various uses. Rice hulls combusted by other technologies may form a crystalline structure that is considered a respirable dust. In the amorphous form, the ash is considered benign. The ash produced by the suspension combustion is $99 \%$ amorphous. Uses include the steel industry for insulation material in the processing, filtration media, and combined with portland cement for a superior concrete. Ash from this type of unit will add income from the ash sales rather than being a disposal cost.

The status of the design is conceptually complete. Sizing and general arrangement of the systems were made for all three. Piping and instrument designs (electrical one lines) were developed and the control schemes were detailed for $5000 \mathrm{~kW}$. A review for the site-specific requirements will be necessary when a particular installation is chosen. Minimal work on the details of the generating system will be required.

Table 4. Heat Rates

\begin{tabular}{|l|l|}
\hline 500-kW Heat Rate: & $38,780 \mathrm{Btu} / \mathrm{kWh}$ or $9772 \mathrm{~kg}-\mathrm{Cal} / \mathrm{kWh}$ \\
\hline 1500-kW Heat Rate: & $24,200 \mathrm{Btu} / \mathrm{kWh}$ or $6098 \mathrm{~kg}-\mathrm{Cal} / \mathrm{kWh}$ \\
\hline $5000-\mathrm{kW}$ Heat Rate: & $16,160 \mathrm{Btu} / \mathrm{kWh}$ or $4052 \mathrm{klg}-\mathrm{Cal} / \mathrm{kWh}$ \\
\hline
\end{tabular}

Although other systems and arrangements afford better heat rates, the overall goal must remain prominent in performing this design. The object is to use rice hulls in the most efficient manner without producing byproducts that create problems. Efficiencies can be enhanced in this type of combustion system but at the cost of manufacturing an ash, which can be considered a hazard. Experience in the field with rice millers shows that the capital cost of these systems is the largest concern. Use of rice hulls allows less efficient consumption if the price is justifiable and no additional problems are created by their use.

The Phase 1 work continued development into three sizes of units that will fit the mill capacities of rice milling equipment sizes; future work will require continuing efforts to reduce the initial capital costs. The possible assistance in this effort will be from manufacturers in countries such as Brazil and China. Qualifications of boiler manufacturers will require the most strenuous effort to ensure the quality, detail design capability, business credibility, warranty assurance, and product support.

Other major engineered equipment, although important to the success of the overall project, is less significant to the combustion/steam generation piece. Turbines, generators, condensers, pumps, feedwater heaters, and the other equipment required are used in power plants with a great variety of fuels. Therefore, having a greater variety of this type of equipment from several sources can ultimately reduce the overall costs of the project.

The expected environmental parameters are air emissions only and are stated in Table 5. No significant differences are expected between unit sizes; therefore, the parameters are applicable to all three designs. The particulate estimate is based on the assumption that a fabric filter will be used for control. Efficiencies of this device are matters of choice for particular locations and may not be included in the plant equipment. Other devices can be used with the penalty of additional emissions of particulate. If a market for this ash is developed, its recovery for sale may be an additional driving force to choose the more efficient collection device. 
Table 5. Air Emissions

\begin{tabular}{|l|l|}
\hline Oxides of Nitrogen-NO $(\mathrm{lb} / \mathrm{mmBtu})$ & 0.05 \\
\hline Reactive Organic Compounds-ROC $(\mathrm{lb} / \mathrm{mmBtu})$ & 0.001 \\
\hline Sulfur Dioxide-SO $\mathrm{S}_{2}(\mathrm{lb} / \mathrm{mmBtu})$ & 0.05 \\
\hline Carbon Monoxide-CO (lb/mmBtu) & 0.159 \\
\hline Particulate--PM10 (gr/dscf) & 0.01 \\
\hline
\end{tabular}

\section{Future Development}

Agrilectric Power, Inc., is marketing the technology as we develop the details of the design. There have been unsuccessful attempts to identify additional projects in the United States. The deregulation of the utility industry, combined with the abundance of natural gas in the rice-growing regions and additional markets developing for rice hulls, severely limit the capability of additional generation with rice hulls. In some regions, additional environmental compliance would open the reexamination of the potential. Deregulation by some states has included a renewable generation portfolio, which could bring about further development.

International development continues to be the most promising for this technology. Project development has been ongoing in South America, particularly in Brazil. The rice industry in Brazil is strong and continues to grow in spite of recent economic problems. Manufacturers have been surveyed and some have been given the opportunity to demonstrate capability. The import duty on U.S. equipment is $25 \%$, imposing a severe pricing disadvantage. Sources for all major equipment required for the PGU have been identified in Brazil with confidence that the standards used would provide a reliable system for this application.

Initial discussions have begun with manufacturers in China. Preliminary investigation indicated that the Chinese do not have detail design capability in the boiler manufacturer's organization. It was thought that the detailed design would have to be performed by design institutes that are fragmented into specialties and no one organization would be able to perform an overall design. This capability is a requirement because of the warranty serviceability requirements. Discussions with the manufacturers proved that they do have all the required capabilities and are very interested in pursuing this type of business arrangement. The design for the three units will have to be modified to coordinate with the turbine manufacturers in China who have chosen a different set of steam conditions for the common usage in small power generating plants.

Another effort to assemble a project in South America was made earlier this year when an engineering/ construction company was asked for a cost proposal. The requirements of the project were to use U.S. equipment and package it into modules on the Texas Gulf coast. The equipment would then be shipped to South America for assembly on the plant site. This too, proved to be too expensive.

Future marketing and development efforts will continue to pursue international markets in the regions discussed earlier. The design concept discussed here provides a starting place for discussions and a realistic look at costs for this technology, but much work remains to reduce the costs to complete the marketing process. Agrilectric Power, Inc., and its partner Satake Corporation will continue to work with the Chinese as that method appears to be the most likely road to success. 


\title{
Bechtel National Incorporated
}

\author{
Subcontractor: \\ Bechtel National Incorporated \\ 45 Fremont Street \\ Contracting Party: \\ San Francisco, CA 94105-1895 \\ Subcontract Title: \\ Sandia National Laboratories \\ Subcontract No.: \\ "Small Modular Biopower Project" \\ SNL BC-0002B \\ Period of Performance: \\ 26 May 1998 through 30 Nov 1999 \\ Subcontract Contact: \\ Mr. Babul Patel, Tel. (415) 768-1200
}

\section{Introduction}

This report represents the final product in response to the SNL contract to evaluate the feasibility of developing an SMB system. The effort supports the U.S. Department of Energy's (DOE) Biomass Power Program, whose goal is to develop SMB systems that are fuel-flexible, create minimal impact on the environment, are efficient and simple to operate, and fall in the power generation range of $5 \mathrm{~kW}$ to $5 \mathrm{MW}$ electricity for domestic and international markets.

The study includes quantifying the domestic and international markets requiring industrial biomass power generation systems ranging between $800 \mathrm{~kW}$ and $1600 \mathrm{~kW}$, identifying and quantifying the biomass fuels available in these markets, and evaluating these markets from economic and environmental standpoints. The preliminary system design expands on the present introductory design by identifying technical issues imposed by the market such as the appropriate system size, modularity requirements for transport, and local installation constraints. The effort also included pursuing strategic partnerships with engine manufacturers to package an entire SMB unit.

The Bechtel Technology and Consulting group of Bechtel National Inc. (BNI) led this effort with its subcontractor PRM Energy Systems, Inc. (PRME) of Hot Springs, Arkansas, and its affiliate Primenergy of Tulsa, Oklahoma.

The basis for the SMB system is the commercial KC gasifier. PRME owns the rights to the technology. PRME has been providing commercial KC gasifiers for industrial applications since the early 1980s. To date PRME has installed 18 of these gasifiers in a range of sizes from $8 \mathrm{MMBtu} / \mathrm{h}$ to $290 \mathrm{MMBtu} / \mathrm{h}$. These installations provide process heat, process steam, electricity, and in many cases a combination of all three energy types.

\section{Potential Markets}

A review of the present combustion turbine and reciprocating engine markets indicates that the largest market for distributed engine systems is in the 5- to $2000-\mathrm{kW}$ size range. Sources indicate that most of the combustion turbines during 1996 and 1997 were shipped to the Far East, whereas the largest reciprocating engine markets appeared to be in North America and Europe.

Rice mills constitute a target market for the KC gasifier SMB system. Market studies show that Malaysia has more than 70 mills that could generate $800 \mathrm{~kW}$ or more, the Philippines and Thailand more than 100 mills each that could support an $800-\mathrm{kWe}$ system. Information regarding the exact size of the mills in India and China was not obtained; however, the two countries produce more than $50 \%$ of the world's rice. Given that both countries have power shortages, they have potential markets for the SMB system. 
The lumber industry also represents a unique market in which a waste resource could be used for power generation. Plywood factories normally require more power than sawmills and may support a 500- to 800-kWe system more readily in a captive power setting than would a sawmill. The Indonesian plywood factories studied require an average diesel system of $850 \mathrm{kWe}$. The waste residues from the factories can support $850-\mathrm{kWe}$ to 1.5-MWe systems.

Most clients for the SMB system can maintain a system that requires O\&M similar to a diesel generation system. The technical capabilities and spare parts will be considered in the SMB design. Load profiles for potential clients and typical industries, which indicate that a turndown ratio of $50 \%$ to $60 \%$ is required, were reviewed.

\section{Fuel Resources}

Abundant resources exist for the SMB KC gasifier system in the form of crop or food processing residues. The KC gasifier can operate on 17 fuel sources, of which rice hulls, rice straw, wheat straw, lumber, corn cobs, and switchgrass residues were reviewed. Residues from the palm oil process were also estimated; however, empty fruit bunches (EFB) and palm nut shells have not been proven in the KC gasifier. The amount of residues and their subsequent potential power production were estimated based on crop production and independent studies. Table 6 summarizes the estimates of the total resource and power available. Electricity conversion efficiencies range from $18 \%$ to $22 \%$ depending on the resource, not taking into account the potential thermal energy available from the exhaust. The authors do not claim that the potential energy translates to market potential. The information indicates only the potential power production.

Table 6. Fuel Resource Quantities and Energy Production Potential

\begin{tabular}{|l|r|r|}
\hline Crop/resource & 1000 tons & $\begin{array}{r}\text { Potential } \\
\text { MWe }\end{array}$ \\
\hline Rice Hulls & 106900 & 5580 \\
\hline Rice Straw & 534700 & 33743 \\
\hline Wheat Straw & 579588 & 30263 \\
\hline Corn Cobs & 633600 & 112540 \\
\hline Wood Residue & & 45000 \\
\hline Cotton Gin Trash & 48183 & 2925 \\
\hline Switchgrass & 84400 & 8346 \\
\hline Empty Fruit Bunches & 7440 & 402 \\
\hline
\end{tabular}

\section{Financial Analysis}

Financial analysis entails funding the new concern and determining the true costs of the SMB unit. Working capital requirements will be sought from a variety of sources including equity funds, potential strategic investors, and venture capitalists. These sources will be assessed, tested, and prioritized and the most advantageous working capital source will be chosen.

Detailed costs for the SMB unit based on manufacturing, assembly, installation, O\&M, and fuel costs have been established. The nominal delivered electricity cost for the units, under the scenario where there are no fuel costs, is approximately $4.9 \mathrm{c} / \mathrm{kWh}$ for the $1600-\mathrm{kW}$ unit and $8.0 \phi / \mathrm{kWh}$ for the $800-\mathrm{kW}$ unit. These prices assume a $7.5 \%$ interest rate for a 7 -year term and $25 \%$ equity. According to published equipment prices for competing distributed energy technologies, when fuel prices exceed \$2/MMBtu on combustion turbine units and $\$ 4 / \mathrm{MMBtu}$ with diesel generation systems, the 1.6-MW SMB unit has a lower levelized energy cost over a 15-year book life. 


\section{System Design}

The SMB system based on the KC gasifier has been designed in two sizes, $800 \mathrm{kWe}$ and $1600 \mathrm{kWe}$. The model KC8 gasifier will be included in packaged systems, which require $800 \mathrm{~kW}$ or less, and be designated "Model KC8-800." The model KC12 gasifier will be included in packaged systems that require $1600 \mathrm{~kW}$ or less and be designated "Model KC12-1600." The SMB systems consist of the gasifier system, producer gas cleanup, and a spark-ignited internal combustion engine (ICE).

The KC gasifier system typically includes the following equipment: fuel metering bin, continuous flow weigh meter, reactor/gasifier, refractory lined reactor gasifier, cooling water system, water-cooled ash discharge conveyors, multi-zoned air supply, rotary feeders, and instrumentation required to provide automatic control over the process. The entire gasification/combustion process, from metering to ash discharge, can be controlled manually or electronically.

In the producer gas cleaning system, the first preparatory step is cooling the producer gas from the evolution temperature. The initial cooling is accomplished by indirect heat exchange with air or water. Secondary cooling, ash, and initial tar are removed by direct liquid scrubbing. Exiting the liquid scrubber, the gas is finally mechanically scrubbed of tar, cooled in a heat exchanger with cooling water from the external cooling tower, and slightly boosted in pressure. The clean producer gas is premixed with heated combustion air before being injected into the ICE.

The ICE is a V-16 with a dry turbo-compressor and electronic ignition. The engine is started with a 24-volt direct current starting motor. The engine is cooled by heat-exchanging internal cooling water with radiator cooling. All necessary pumps, exchangers, piping, and cooling water tower are included. Each engine is direct coupled to an electrical generator and each engine-driven generation set is mounted on a common frame.

The integration of the gasifier and gas cleanup system to produce a consistent quality producer gas to sustainably run an ICE has not been demonstrated. The future work and efforts should be directed toward demonstrating reliable power from the $\mathrm{KC}-8$ system and tie-in with the grid.

Details regarding the producer gas production, process flow charts, and process flow diagrams are provided. A preliminary analysis of the gas produced from the $\mathrm{KC}$ gasifier indicates that the producer gas may be an acceptable fuel for a molten carbonate fuel cell with preprocessing of the gas. Fuel cells may be potential power generation sources in an SMB system once the technology becomes fully commercial. They are not considered viable options at this time.

Both the model KC8-800 and the model KC12-1600 have been designed so they can be packaged for export and transported by ship, rail, or truck in standard containers. Research indicates that infrastructure is present for most probable sites. The modules have been designed to maximize shop assembly and minimize field erection requirements.

\section{Environment and Safety}

The SMB system based on the $\mathrm{KC}$ gasifier is designed to meet the World Bank General Environmental Guidelines. Initial tests indicate that the $\mathrm{SMB}$ unit will meet $\mathrm{NO}_{\mathrm{x}}$ and $\mathrm{SO}_{2}$ emission limits. Particulate, solid, and liquid waste limits will be tested in Phase II. Design modifications will be made if necessary to meet the General Environmental Guidelines. 
Impacts from manufacturing, shipping, installation, maintenance, operations, and decommissioning are similar to those of combustion turbine-, and diesel-generated power units of similar capacities. Operations have positive impacts on the environment by displacing fossil fuels with an agriculture residue. The agriculture residue is a sustainable, renewable resource. The $\mathrm{CO}_{2}$ emitted during the conversion process is absorbed by subsequent crops grown.

The SMB unit based on the KC gasifier is designed with state-of-the-art instrumentation and built-in safety interlocks to provide automatic operation and protect personnel and equipment in the event of upset operating conditions.

\section{Future Development}

$\mathrm{KC}$-Systems is in an excellent position to capitalize on the vast market for SMB systems. The company's products are based on proven technology and its founders have a long track record of implementing successful biomass projects in the national and international marketplaces. The company's vision, mission, and goals are realistic, sound, and achievable.

The initial management team is made up of experienced professionals with positive and aggressive attitudes toward the success of this new venture. Several contacts with potential marketing and development partners are in place and require only further evaluation and negotiation. Supported by its parent companies, the new entity can start up and grow without additional capital; however, to expand rapidly and achieve its maximum potential, additional capital will likely be necessary.

KC-Systems' products are competitive in most markets. The company's initial system sizes will span approximately one-third of the total current market for competitive fossil fuel systems. The systems' modularity and future scaled-up versions increase its coverage to more than one-half of the marketplace.

KC-Systems planned mode of production and operation is sound. The initial manufacturing of the gasification systems in Tulsa will ensure good quality control and efficient production. Adequate facilities are currently available for the first two years of production. The potential future procurement and manufacturing of portions of the systems on the local economy may provide opportunities for lowering costs.

The sales and distribution plans will provide for quick penetration into the target markets. The opening of dealerships within these markets will give immediate access to the dealers' current clients and provide for superior customer service.

The risks for this business venture are manageable.

KC-Systems presents a tremendous opportunity for its founders, partners, dealers, and suppliers to be the early leaders in the SMB field of renewable energy. 


\title{
BIOTEN General Partnership
}

\author{
Subcontractor: $\quad$ BIOTEN General Partnership \\ 10330 Technology Drive \\ Knoxville, TN 37932 \\ Contracting Party: \\ Midwest Research Institute, National Renewable Energy Laboratory \\ "Small Modular Biopower Project" \\ ACG-8-18073-04 \\ Subcontract No: \\ Period of Performance: \\ 16 Jun 1998 though 31 Mar 1999 \\ Subcontractor contact: \\ H.W. Arrowsmith, Tel. (423) 675-2130
}

\section{Introduction}

BIOTEN Corp. (BIOTEN) of Knoxville, Tennessee, is the corporate successor of BIOTEN Partnership ("BIOTEN GP"), a general partnership of BIOTEN, LLC ("LLC") and EUA BIOTEN, Inc. ("EUA"), a wholly owned subsidiary of Eastern Utilities Associates, Boston, Massachusetts.

BIOTEN has developed a generation system that produces electricity using biomass fuels directly fired in conjunction with a combustion turbine ("BIOTEN process"). The BIOTEN process utilizes the direct firing of biomass fuel in an offset, pressurized combustor whose combustion gases are cleaned in a cyclone filter and injected into the compressor turbine. BIOTEN modifies the combustion turbine by replacing the original fuel combustion chamber with a center section. The BIOTEN process is presented in Figure 1. The box labeled "Processed Fuel" represents a BIOTEN biomass fuel processing system designed to convert the raw "Biomass Fuel" into the "Dry Fuel" or "Fuel Dust" required for the BIOTEN combustion process. The BIOTEN combustion turbine system is composed of the components identified as "Combustor," "Cyclone Filter," "Gas Generator," and "Power Turbine." The generation of electricity involves the components "Gear Box" and "Generator." The "Step-Up Transformer" is part of the system to distribute the generated power to the power purchaser. The "Brake" is part of the safety systems built into the BIOTEN process to handle emergency situations.

The BIOTEN process has several environmental and economic advantages over the competing technologies:

- The BIOTEN process requires no process water because there is no steam cycle; thus, there is no water makeup or wastewater discharge.

- The process utilizes renewable biomass fuel, which is low in sulfur and nitrogen; thus, the $\mathrm{SO}_{2}$ and $\mathrm{NO}_{\mathrm{x}}$ emissions impacts are generally less than those of fossil fuels.

- The utilization of biomass fuels results in a zero net input of atmospheric $\mathrm{CO}_{2}$ to the world greenhouse gases.

- The BIOTEN process can be installed in 10 months or less.

- The BIOTEN process has a low capital cost and an efficiency that results in very competitive production costs. 


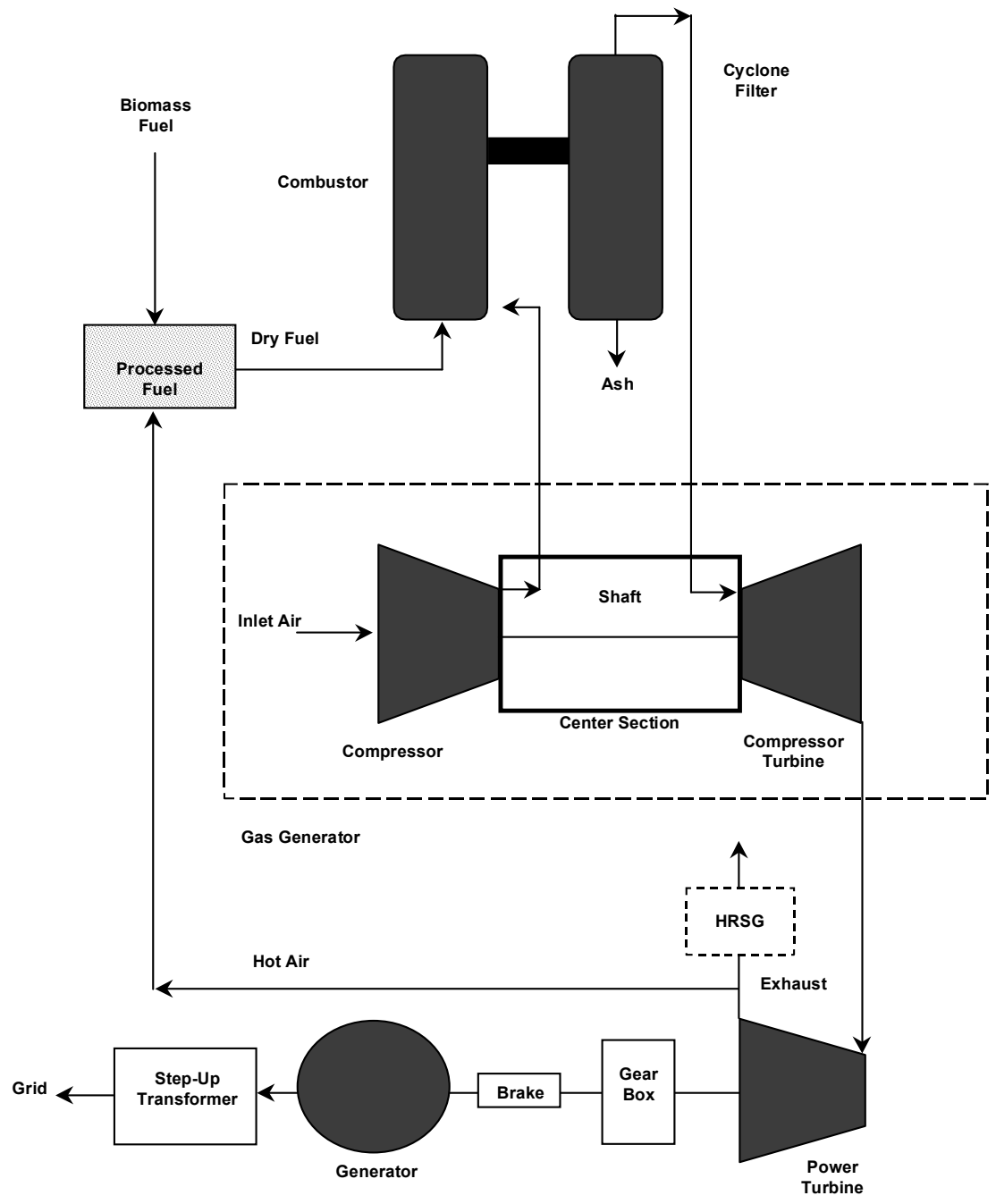

Figure 1. The BIOTEN Process

\section{Potential Markets}

This report analyzes the suitability of the BIOTEN process to be used in three countries or markets with distinctly different features. BIOTEN has performed significant research on India, the Philippines, and Canada in an effort to understand each country's market potential for applying the BIOTEN technology. We have contacted numerous prospective customers for our generating plants, including sugarmill owners, rice millers, lumber operations, paper and pulp facilities, waste disposal companies, and other biomass-related companies. The following are summaries of BIOTEN's market and resource assessments for the three countries studied. 


\begin{tabular}{|c|c|c|c|}
\hline \multicolumn{4}{|c|}{ A. SUMMARY OF MARKET ASSESSMENT } \\
\hline & India & $\underline{\text { Philippines }}$ & Canada \\
\hline $\begin{array}{l}\text { 1. Application of } \\
\text { BIOTEN Process }\end{array}$ & $\begin{array}{l}\text { - Simple cycle } \\
\text { - Use of waste heat to } \\
\text { enhance overall } \\
\text { efficiency }\end{array}$ & - Simple cycle & $\begin{array}{l}\text { - Simple cycle } \\
\text { - Use of waste heat } \\
\text { to enhance overall } \\
\text { efficiency }\end{array}$ \\
\hline 2. Market Size & 3,500 MW & $250 \mathrm{MW}$ & $1,000 \mathrm{MW}$ \\
\hline 3. Module Size & 3-6 MW & $\begin{array}{l}5-6 \mathrm{MW} \\
1-3 \mathrm{MW}\end{array}$ & 5-6 MW \\
\hline $\begin{array}{l}\text { 4. Competing } \\
\text { Technologies }\end{array}$ & \multicolumn{3}{|c|}{ NONE IN BIOTEN CAPACITY SIZE RANGE } \\
\hline $\begin{array}{l}\text { 5. Permitting } \\
\text { Requirements }\end{array}$ & \multicolumn{3}{|c|}{ BIOTEN PLANT WILL SATISFY ALL KNOWN REQUIREMENTS } \\
\hline \multicolumn{4}{|c|}{ B. SUMMARY OF RESOURCE ASSESSMENT } \\
\hline 1. Feedstock Suitability & $\begin{array}{l}\text { - Bagasse is } \\
\text { acceptable }\end{array}$ & $\begin{array}{l}\text { - Rice hulls are } \\
\text { acceptable }\end{array}$ & $\begin{array}{l}\text { - Sawdust, trimmings } \\
\text { and bark are } \\
\text { acceptable }\end{array}$ \\
\hline 2. Properties & \multicolumn{3}{|c|}{ CHEMICAL COMPOSITION SUITABLE } \\
\hline 3. Competitive Uses & - Minimum to none & - None & - Minimum to none \\
\hline
\end{tabular}

Other features of these markets are:

India Must import most of its liquid fossil fuel used to produce electricity. Laws have been passed in recent years to encourage the development of private power production. Sugarcane bagasse is a by-product of the sugar manufacturing process with a small- to medium-sized sugarmill capable of producing 5 to $10 \mathrm{MW}$ of exportable electricity.

Philippines Imports most of its fuel. There are large geothermal areas but energy costs are still very high. Laws affecting the disposal of rice hulls have not been enforced because of lack of disposal areas. Availability of rice hull burning plants would encourage enforcement. In many areas, three to ten rice mills produce enough rice hulls to supply a BIOTEN plant.

Canada Has extensive natural resources of energy; consequently, relatively low electricity rates. However, large quantities of sawmill waste are produced and environmental laws are forcing increased costs in disposal.

BIOTEN will focus on India to develop various strategies and business relationships needed to begin to penetrate this market and to develop a model for other international markets. 


\section{System Design}

BIOTEN has designed and constructed a net 5.0-MW commercial demonstration plant (CDP) located at Red Boiling Springs, Tennessee. The CDP is fueled by waste fresh-cut sawdust that is abundantly available in this part of Tennessee. The CDP has gone through several phases of testing and development during the past two years. The major components, including the fuel processor, turbines, pressurized suspension combustor, and cyclones, are based on technologies that are well known and have strong performance and maintenance records with tens of thousands of hours of in-service histories. The BIOTEN basic open cycle generation system design is characterized as a 5.0-MW net output plant operating at $1400^{\circ} \mathrm{F}$ and 120 psig with a mass flow of about 125 pounds per second while consuming approximately 10 tons per hour of biomass. The BIOTEN process plant may be obtained including all equipment requirements from fuel receiving and processing through the utility interconnection, as required by customer specification. The plant will fit on a three-acre site or a parcel of land approximately 300 by 400 feet in size. The construction period is approximately 10 months.

The basic open cycle configuration provides three products. The primary product is electricity. The plant's net generation can be operated as a traditional base load generation plant. A secondary product is the plant's thermal discharge that may be used for drying and/or heating processes. The third product is an ash that contains potassium and other trace elements that support photosynthesis.

The basic fuel supply will normally be a waste stream. Thus, the BIOTEN process promotes the environmentally sound disposal of biomass waste products. The use of biomass fuels will help reach the environmental targets established through the Kyoto, Japan Agreement. The agreement requires nations, especially industrialized ones, to effect significant reductions in greenhouse gases such as methane $\left(\mathrm{CH}_{4}\right)$ and $\mathrm{CO}_{2}$. The BIOTEN process will greatly reduce the agricultural waste dumpings, major sources of $\mathrm{CH}_{4}$ and $\mathrm{CO}_{2}$ gases through the natural decomposition process of any biomass. Furthermore, burning biomass fuels does not generate the excess $\mathrm{CO}_{2}$ associated with it burning fossil fuels because biomass consumes the same amount of $\mathrm{CO}_{2}$ in its growth process as it generates when burned. Potential biomass fuel sources include waste products from lumber mills, forest and right-of-way clearing operations, pulp and paper mills, sugarcane mills, rice mills, and agricultural waste such as wheat and corn stalks.

The BIOTEN process promotes the local environmental wellbeing by:

a. Disposing of waste residues while reducing greenhouse gas emissions and landfill requirements.

b. Reducing the need for fossil fuels by displacing some of the requirements with an inexpensive, locally generated renewable fuel source.

c. Providing electrical and thermal energy for the industrial and manufacturing complexes and the surrounding area; it does not require a large transmission facilities infrastructure.

d. Generating a secondary product, an ash containing potassium and other trace elements, that is usable as the basis for a natural fertilizer and other commercial products. The use of an ash-based natural fertilizer will reduce the need for chemical-based fertilizers, another environmental benefit.

The CDP was sited under the State of Tennessee Environmental Siting Provisions. The Tennessee Environmental Protection Agency mandates emission compliance levels that are either the same as or more stringent than the U.S. Environmental Protection Agency (EPA) requirements.

\section{Future Development}

BIOTEN has some remaining challenges that need to be satisfied to allow significant penetration into India or other world markets. The CDP will be used to prove the viability of the BIOTEN technology and demonstrate its performance characteristics. BIOTEN expects that sufficient data and operating results will be obtained and analyzed during the year 2000 to allow BIOTEN to offer a commercial product on a turnkey 
basis with reasonable commercial guarantees for availability, heat rate, and capacity. The CDP will also allow BIOTEN to test and qualify additional biomass fuels besides sawdust, including bagasse, rice hulls, and tree bark.

BIOTEN has developed an O\&M plan to support the CDP, including operating procedures, preventative maintenance procedures, major overhaul schedules, and operator qualification and training programs. Additional run time at the CDP will allow BIOTEN to verify and fine tune these O\&M procedures. These procedures will also provide the basis for developing the O\&M support infrastructure required in foreign countries.

BIOTEN's vision of itself as a mature business focuses on providing customers worldwide with turnkey technology and customer services to support the development of renewable, clean, and economical electrical and thermal energy. To accomplish this, BIOTEN's services will include engineering, procurement, and construction (EPC) services as well as financing support and O\&M support services as defined by the customer.

To achieve these goals, BIOTEN has developed the following three sets of objectives:

L. Corporate Objectives

1. Build a company recognized as a competent engineering and manufacturing firm that is recognized as a leader in the biomass power generation field.

2. Establish a reputation of quickly responding to potential business opportunities.

3. Operate the CDP on a financially sound and safe basis.

4. Use the CDP to develop approaches that improve the BIOTEN technology related to plant performance, efficiency, reliability, availability, and maintainability.

5. Collect data from CDP operations to optimize the commercial design of the BIOTEN process for as many biomass fuel sources as possible.

6. Develop and maintain a corporate staff that will support the company growth.

B. Business Development Objectives

1. Create and maintain an organization that provides the capability to address rapidly changing market and business opportunities.

2. Develop ongoing business relationships with renewable fuel producers, utilities, consultants, and EPC firms providing services to the electric generation market, power marketing groups, outside financial sources, and O\&M contractors to improve BIOTEN's possibility of expanding its business and satisfying customers' needs.

C. Financial Objective

1. Obtain corporate revenue stream from unit sales and the associated ancillary functions that will allow the company to grow continuously.

BIOTEN's definition of success will be based on a combination of selling BIOTEN process systems worldwide while achieving the corporate, business development, and financial objectives previously discussed. BIOTEN recognizes that most of its unit sales will be foreign.

The United States has a mature electrical generation and distribution system in place. The deregulation activities will not dismantle this structure but will realign it to provide more opportunities for competition. The generation opportunities will provide BIOTEN with the niche market for its products. In some regions of 
the United States biomass-fueled electrical generation is not feasible. However, niche markets will be created for systems in the 5-MW to 10-MW range. This is BIOTEN's target market in the United States. This market will include the lumber and forestry industries, the municipal and landfill operators seeking ways to improve their management programs to extend the useful life of their assets, and some enterprising firms that will combine many resources for the mutual benefit of all parties involved.

Foreign countries that have agricultural foundations represent the largest market opportunity for any form of biomass energy generation. The BIOTEN process will help these countries develop their local infrastructures at feasible and economic rates. Developing nations have the desire to obtain the U.S. and Western European standard of living. However, they recognize this will not happen soon and will require both careful planning and financial support.

A successful BIOTEN will possess the engineering and manufacturing capabilities to satisfy all potential customers. Additionally, BIOTEN will have developed the necessary relationships to support any client with financing, EPC, and O\&M support as required. In terms of unit sales, a successful BIOTEN should be capable of delivering eight stand-alone units, six tandem units, four fuel processing systems, and the associate support functions per year. 


\title{
Carbona Corporation
}

\author{
Subcontractor: Carbona Corporation \\ 4501 Circle 75 Parkway \\ Suite E 5300 \\ Atlanta, GA 30339 \\ Contracting Party: \\ Sandia National Laboratories \\ Subcontract Title: \\ "Small Modular Biopower Project" \\ SNL BC-0002E \\ Subcontract No.: \\ 8 Jun 1998 through 30 Nov 1999 \\ Period of Performance: \\ Mr. Jim Patel, Tel. (770) 956-0601
}

\section{Introduction}

This report has been prepared by Carbona Corporation as part of DOE's SMB project. The feasibility study is Phase 1 of a three-phase program that will result in a demonstration of a small-scale biopower system.

The study is based on Carbona's updraft gasification technology, which is an atmospheric, fixed bed gasifier. Several plants based on this technology operates in Scandinavia. The power plant consists of a fuel handling section, gasifier, boiler, and a steam turbine generator.

The study has considered the feasibility of three sizes of power plants: 1,3 , and 5 MWe. All the plants are combined heat and electric power (CHP) producers. The preferred biomass fuel is woody biomass and the preferred markets are timber sawmills or district heating plants. The feasibility study includes a market and resource assessment, a preliminary design of the power plant, an environmental and cost analysis, and an integrated business and commercialization plan. The specific design is based on a 3-MWe power and $19 \mathrm{MMBtu} / \mathrm{h}$ heat producing biopower plant.

The results of the feasibility study show that in the markets evaluated such a biomass-based power plant can supply all the energy to a sawmill or to district heating (CHP) at attractive economics. Carbona and its partners propose to build and operate an updraft gasifier biopower (UGB) plant either at a sawmill in Ghana or at a district heating plant in Denmark under Phase II of the SMB project.

\section{Potential Markets}

The UGB system is a CHP plant. The biomass fuel for the UGB is wood waste either from forestry as wood chips or timber and sawmill operations. Therefore, the primary market for the UGB system is a sawmill or a community in a cold climate with a nearby forest industry or availability of wood residue. Both potential markets need electric power and some form of heat in the sawmill for drying and in the community for heating. Moreover, the planned size range of the UGB system - 1, 3, and $5 \mathrm{MWe}$ - is suitable for most of the market potential. Another requirement for the potential market for the community application is that it should be remotely located and therefore have no grid connection for electricity or that power price is very high. For both applications the price differential between wood waste and alternative fuels such as liquid petroleum and natural gas should be relatively large.

In the United States today the cost of electricity (COE) is very low $(2-3 \phi / \mathrm{kWh})$, mainly because of low natural gas prices. Under these circumstances, the UGB system cannot economically compete for new customers. Remotely located communities near forestry industries are the only potential markets. However, several contacts with them have been unfruitful, mainly because of institutional barriers. 
Therefore, the most attractive markets are international - in Scandinavia and the Baltic states and in developing countries with forest industries and where the alternative fuel prices are high. These countries are in Central and South America, West and East Africa, Asia-Pacific, Scandinavia, and the Baltic states. Some of the countries identified as promising potential markets in these regions are Brazil, Chile, Ghana, Kenya, India, China, Thailand, Denmark, Sweden, Latvia, and Estonia. The market and resource assessment in this study was for the two most promising areas: West Africa and Scandinavia.

The Danish government intends to continue the development of renewable energy at an average annual rate of $1 \%$. This entails renewable energy increasing its share of the energy supply to about $35 \%$. A gradual increase in the use of biomass at power plants should amount to 1.2 million tonnes of straw and 0.2 million tonnes of wood chips annually by 2000 . Approximately 60 small towns should be converted to biomass-based district heating.

Data from the Food and Agriculture Organization of United Nations' database show that four African countries, which are all well-known for their large sawmill industries, have a market potential for at least 70 UGB plants of 3 MWe. These four countries are Ghana, Ivory Coast, Cameroon, and Nigeria.

The total investment cost of the 1-, 3-, and 5-MW UGB plants was estimated using standard costing practices. Because of the large size of the gasifier, for the UGB plant of $5 \mathrm{MW}$ capacity two gasifiers will be assumed to supply gas to one gas boiler. The investment costs are summarized in Table 7.

Table 7. Investment Costs

\begin{tabular}{|c|l|}
\hline Nominal capacity & Total investment cost \\
\hline $1 \mathrm{MW}$ & $\$ 3.88$ million \\
\hline $3 \mathrm{MW}$ & $\$ 5.88$ million \\
\hline $5 \mathrm{MW}$ & $\$ 8.52$ million \\
\hline
\end{tabular}

The COE is $5-7 \phi / \mathrm{kWh}$ depending on price of biomass fuel and heat.

\section{System Design}

The power and heat generating power plant system described in this feasibility study is based on wood-based biomass. The fuel is gasified in an atmospheric pressure updraft gasifier. The low calorific value (LCV) product gas produced in the gasifier is burned directly in a boiler that generates high-pressure steam. Steam is utilized in a back-pressure steam turbine generating power and provides heat for district heating. The rest of the plant is a typical arrangement of conventional equipment.

The gasification plant (Figure 2) is to convert solid biomass fuel to product gas. The gasification plant is served by a fuel receiving station combined with covered fuel storage in addition to an open air fuel reclaim area. A conveyor transfers the fuel from the storage to the feeding system. The feeding system is piston type, gas-tight feeder located atop the gasifier. The gasifier is an air-blown updraft fixed bed gasifier. It comprises a refractory-lined shaft furnace and rotary grate. The fuel drops to the top of the fixed bed in the gasifier. First it will be dried by the upward product gas flow. In this drying process the product gas cools to about $480^{\circ}-$ $660^{\circ} \mathrm{F}\left(250^{\circ}-350^{\circ} \mathrm{C}\right)$, the exit gas temperature of the gasifier. The dried fuel then moves downward in the fixed bed, countercurrent with the product gas, through the gasification zone of about $1800^{\circ} \mathrm{F}\left(1000^{\circ} \mathrm{C}\right)$ temperature to the oxidation zone. The residual ash accumulates in this oxidation zone, near the grate. The gasifier ash is removed through the bottom of the gasifier by gravity through a valve systems into the ash containers and is then landfilled. 
The gasification air is fed through the rotating grate located in the bottom of the gasifier reactor to enable proper air distribution in the fixed bed. The air is preheated and humidified using steam before being fed into the gasifier. The steam is to control the gasification temperature (i.e., prevent ash sintering) in the lower bed area. The LCV product gas is generated in the gasification area. The product gas exiting the gasifier is directed to the gas boiler through the gas pipe. The gas pipe is short to minimize tar condensation. The gas is burned in a gas boiler equipped with a special gas burner suitable for LCV gas combustion.

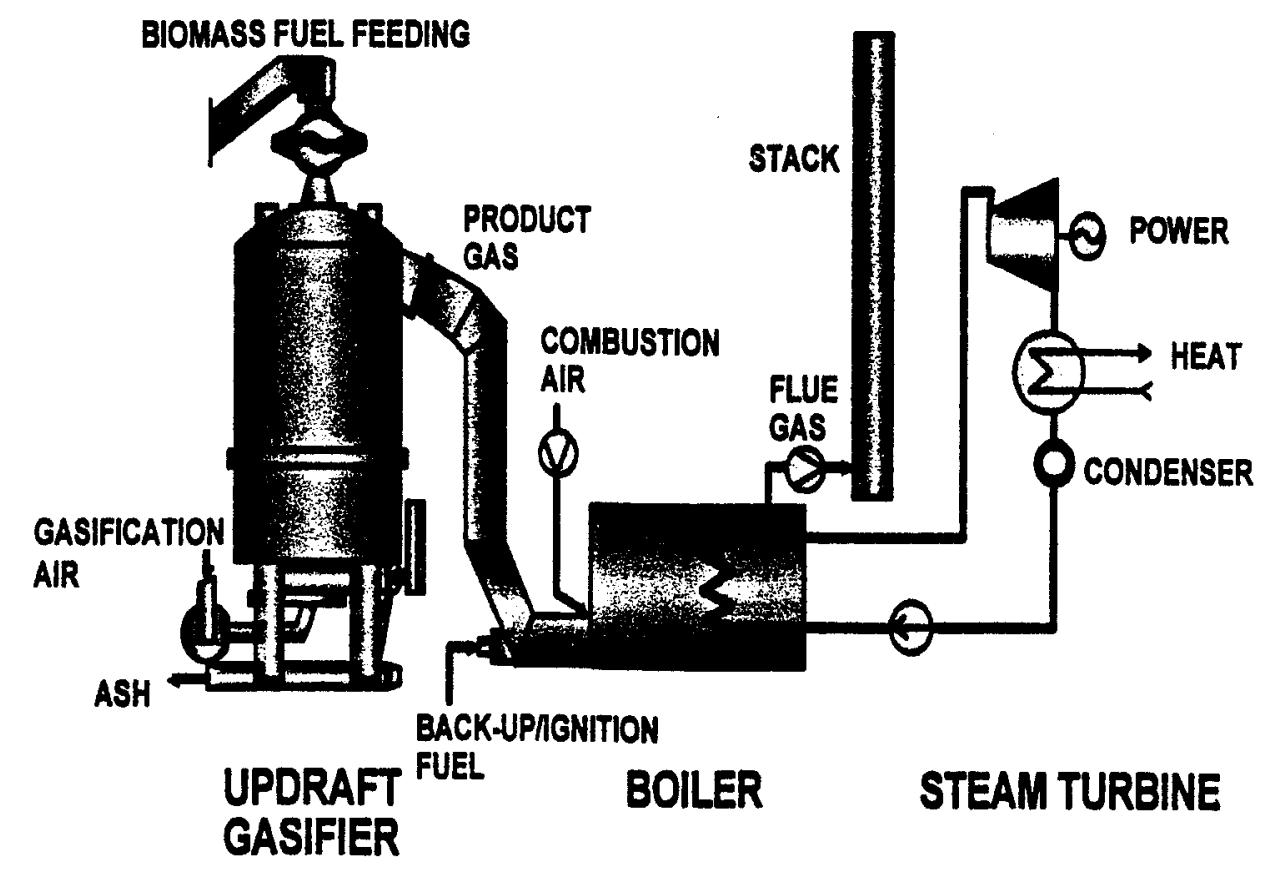

Figure 2. Updraft Gasifier Biopower System

The emissions of UGB plant as compared with emission limits required by the World Bank are listed in Table 8.

Table 8. UGB Plant Emissions

\begin{tabular}{|l|l|l|}
\hline & $\begin{array}{l}\text { Pollutant } \\
\text { UGB plant }\end{array}$ & $\begin{array}{l}\text { Emission rate } \\
\text { World Bank limit }\end{array}$ \\
\hline $\mathrm{SO}_{2}$ & $0,009 \mathrm{tpd} / \mathrm{MWe}$ & $0,2 \mathrm{tpd} / \mathrm{MWe}$ \\
\hline $\mathrm{NO}_{\mathrm{x}}$ & $100 \mathrm{mg} / \mathrm{MJ}$ & $260 \mathrm{mg} / \mathrm{MJ}$ \\
\hline $\mathrm{CO}$ & $25 \mathrm{mg} / \mathrm{MJ}$ & $\mathrm{n} / \mathrm{a}$ \\
\hline Particulate & $10 \mathrm{mg} / \mathrm{nm}^{3}$ & $50 \mathrm{mg} / \mathrm{nm}^{3}$ \\
\hline
\end{tabular}

The overall efficiencies of the three sizes of the UGB plants are shown Table 9. 
Table 9. Overall Efficiencies of UGB Plants

\begin{tabular}{|c|c|c|c|c|}
\hline $\begin{array}{c}\text { Nominal } \\
\text { Capacity } \\
\text { MW }\end{array}$ & Electric Power & Heat & $\begin{array}{c}\text { Electric } \\
\text { Efficiency } \\
\text { (LHV) }\end{array}$ & $\begin{array}{c}\text { Overall } \\
\text { Efficiency } \\
\text { (LHV) }\end{array}$ \\
\hline 1 & 1.0 & 3.66 & 18.6 & 82.0 \\
\hline 3 & 3.0 & 8.37 & 21.9 & 82.7 \\
\hline 5 & 5.0 & 13.6 & 22.4 & 83 \\
\hline
\end{tabular}

\section{Future Development}

Carbona intends to supply the UGB systems in the identified markets on a turnkey basis. To achieve this, strategic partnerships will be formed with a local company in each country. Carbona has the basic engineering knowhow of the UGB system and has the background from experience in supplying UGB systems in Scandinavian countries through its sister company in Finland. There are 10 operating plants based on UGB principles, located mostly in Finland.

For Scandinavia and the Baltic states Carbona has entered into an alliance with FLS miljø a/s. Ultimately Carbona will solidify this agreement for delivering UGB plants on a turnkey basis in Europe. For Ghana, Carbona has already formed a cooperation with a company called Waypoint Ltd. Similarly, Carbona has also formed a cooperation with a company called IBIL Tech Limited in India for that market. A potential customer has also been identified in India for a demonstration project.

The short-term goal is to build and operate a demonstration plant for each of the two primary applications of the UGB system - sawmill and local community. Two commercial plants should be sold based on the results of the demonstration plants. In the midterm the goal is to build UGB systems in four of the main potential market countries to establish a broad base for future business. Also during this period efforts will be made to improve the efficiency and cost competitiveness of the UGB system. One approach will be to develop gas cleanup techniques so the steam turbine power block can be replaced by a gas engine. Also, the feedstock base for the system will be expanded to include agricultural waste and retrieve derived fuel. In the long term for the business to be successful, at least five UGB systems should be sold annually, and the U.S. market for biomassbased power must be established. This will require innovative approaches in financing, project development, and new partnerships.

As part of the commercialization of the UGB system, an aggressive marketing plan will be implemented. An initial step has already been taken by signing up partners for sales and marketing efforts on a local level in Scandinavia, the Baltic states, Ghana, and India. Also, quickly establishing the demonstration plants to aid in the marketing effort whereby customers can inspect and evaluate the results of an operating unit is essential. Therefore, the initial marketing efforts will be concentrated in Scandinavia, the Baltic states, Ghana, and India. 


\section{Community Power Corporation}

$\begin{array}{ll}\text { Subcontractor: } & \text { Community Power Corporation } \\ & \text { 5796 East Chenango Ave. } \\ & \text { Aurora, Colorado 80015 } \\ \text { Contracting Party: } & \text { Midwest Research Laboratory, National Renewable Energy Laboratory } \\ \text { Subcontract Title: } & \text { "Small Modular Biopower Project" } \\ \text { Subcontract No: } & \text { NREL ACG-8-18073-01 } \\ \text { Period of Performance: } & \text { 4 Jun 98 through 30 Sep 99 } \\ \text { Subcontract Contact: } & \text { Robb Walt, Tel. 303- 690-7869 } \\ & \text { Email: robbcpc@aol.com }\end{array}$

\section{Introduction}

Based on Community Power Corporation's (CPC) need for large numbers of small biopower systems for rural electrification projects in Indonesia and its inability to purchase a commercially proven system, in 1997 CPC formulated a strategy to develop a family of SMB systems to electrify off-grid communities. In January 1998, CPC created a new biopower division with the collaboration of Dr. Thomas B. Reed, an internationally recognized expert on gasifiers. Based on CPC's preliminary assessment of market requirements, Dr. Reed identified several necessary improvements to current state-of-the-art SMB systems. Compared to current power gasifiers, these improvements focused on developing a new modular "Turn Key, Tar Free" high-energy gasifier, much smaller in size, with fewer components, no liquid effluents or hazardous wastes, much lower capital and operating costs, reduced maintenance, minimal civil works, and greater load-following capability.

Under Phase 1 of the SMB project, CPC conducted market and biomass resource assessments for 12- to 25-kWe SMB systems in three countries: Indonesia, Brazil, and the Philippines. These field studies showed conclusively that there was a significant and growing rural electrification market for CPC's SMB system.

The objectives of Phase 1 were as follows:

1. Identify potential markets for CPC's proposed SMB system.

2. Define the characteristics of the system required by the markets.

3. Identify technical issues to be resolved for the systems to meet market requirements.

4. Identify and evaluate the environmental issues associated with the proposed system.

5. Investigate strategic partnerships required to finance the business development.

6. Develop a detailed engineering design study for the prototype SMB system.

7. Perform a preliminary hazard and operability study of the prototype.

The accomplishments during Phase 1 were as follows:

\section{Market and Pilot Project Identification}

- Conducted successful market assessment in Indonesia, Brazil, and the Philippines.

- Identified community power and rural industries markets for 12- to 25-kWe SMB systems in the Philippines (2000), Indonesia (5000), Brazil (2000), and Alaska/United States (TBD).

- Began preparing two specific pilot project sites to demonstrate CPC's SMB system in the Philippines.

- Identified additional pilot project sites for CPC's SMB system in Indonesia and Brazil. 


\section{$\underline{\text { SMB System Design and Development }}$}

- Developed a set of detailed market-driven specifications for CPC's new SMB system based on the comprehensive, on-the-ground market and customer surveys in three countries.

- Assembled a world-class design and engineering team to develop CPC's SMB prototype.

- Designed, fabricated, and tested a pre-prototype SMB power gasifier, including cleaning and cooling components, automated fuel feeder, an ash extraction system, and full instrumentation and data logging systems. Fifteen fully instrumented runs of the pre-prototype power gasifier have been conducted to determine the optimal design and operating parameters for a CPC "Turn Key, Tar Free" power gasifier during Phase 2. The pre-prototype system was demonstrated at NREL on September 14, 1999.

\section{$\underline{\text { Strategic Relationships }}$}

- Established a formal strategic relationship with Shell Renewables (SR) to commercially develop CPC's SMB system and to apply the system in rural electrification projects.

- In the Philippines, established formal relationships through MOUs and MOAs with two provincial governments, electric cooperatives, and the Philippines Coconut Authority for two SMB pilot projects.

- Established a relationship with the Development Bank of the Philippines to finance SMB system applications.

\section{Potential Markets}

During Phase 1, CPC conducted field-based market studies for its SMB system in the Philippines, Indonesia, and Brazil. These studies showed conclusively that the primary market for CPC's SMB system is the electrification of off-grid communities. Two related markets were also identified for electrical and thermal energy for small-scale rural industries (agro-processing, crop drying, ice making, light manufacturing) and community needs for hot water and cooking.

There are more than 100,000 unelectrified communities in the Philippines, Indonesia, and Brazil. About $70,000(70 \%)$ are in Indonesia, 20,000 (20\%) in Brazil, and about 10,000 (10\%) in the Philippines. About 50\% or 50,000 are inaccessible because of lack of roads, do not have a sustainable biomass source, or are candidates for electrification by the utility during the next 10 years. Of the remaining 50,000 communities, about one half, or about 25,000 communities could pay for energy services from an SMB system. CPC's experience suggests that the potential sales of SMB systems in these countries over a 10-year period would be 2000 to 3000 systems or roughly $10 \%$ of the potential market. Of the three countries studied under Phase 1 , the Philippines was selected as the most promising near-term market because of its stability, strong economic growth, abundant and appropriate agricultural residues (coconut shells and corn cobs), and strong government support for private sector participation in rural electrification projects.

\section{Philippines: Markets for CPC's SMB Systems}

With 70 million people, 7107 islands, a strong and growing economy, a stable government focused on sustainable rural development, and more than 4 million rural households without access to electricity, the Philippines offers a readily accessible $\$ 300$ million annual market for renewable energy-based electricity services.

The same conditions that prohibit the use of conventional technologies make SMB systems ideal. The typical unelectrified region in the Philippines consists of hundreds of small clusters of 30 to 100 households surrounded by thousands of individual homes scattered throughout the countryside. In regions where coconut is the main crop, CPC's SMB systems are ideal for providing compact communities with $220-\mathrm{V}$ accelerated current electricity services. Rural enterprises and community services such as water pumping, street lights, 
health clinics, schools, churches, community centers, stores, and workshops can also be served by CPC's 10to $25-\mathrm{kWe}$ SMB systems.

\section{Indonesia: Markets for CPC's SMB Systems}

With 25 million unelectrified homes, mostly located in vast agricultural areas rich in biomass residues, Indonesia is an ideal market for SMB systems. CPC's eight years experience in Indonesia and field studies conducted under Phase 1 of the SMB project showed that more than half, or 12-15 million households (60,000 communities) are located in agriculturally rich and more prosperous agricultural regions. These rural households, which spend close to $\$ 1$ billion each year for inferior and environmentally damaging energy services from kerosene and automobile and dry cell batteries, constitute CPC's primary target market for SMB power systems in Indonesia.

CPC will access this market for SMB systems through its joint venture in Indonesia, PT. Bakrie Renewable Energy Systems (PT. BRES). Working in concert with various market aggregating sponsors, CPC will use SMB pilot projects to create the opportunity to serve the nearly 3000 unelectrified agricultural communities that have been established during the past three decades. PT. BRES will also initiate sales of SMB systems to one of the Bakrie Group's largest and most profitable business entities, Bakrie Sumatra Plantations (PT. BSP). PT. BSP is a major owner, operator, and developer of plantations for palm oil and rubber wood. Hundreds of communities located on PT. BSP's many plantations are without access to electricity and represent an attractive potential market.

\section{Brazil: Markets for CPC's SMB Systems}

CPC's field visit and market reconnaissance study in Brazil during Phase 1 showed that Brazil represents one of the world's largest potential markets for CPC's SMB power systems. However, because of the vastness of the country and a generally underdeveloped interior whose economy consists primarily of small-scale agriculture and forest products enterprises, supported by small, marginally accessible communities (typically with 20 to 50 homes), capturing and servicing this market presents a unique and difficult challenge. The typical household income in the target market communities is reported to be in the range of $\$ 200$ per month, which suggests an excellent ability to afford a basic level of energy services.

The long legacy of government-supported and -controlled monopolies for generating and distributing electricity and high-cross subsidies for rural electrification, is a barrier to opening up the unserved markets (rural and isolated communities) to a market-driven supply of energy services. However, the ongoing privatization of state-owned utilities, changes in regulation policies, and a gradual breakdown of service territory monopolies are opening up new opportunities for the commercial supply of renewable energy-based power systems and energy services to unserved communities. Another positive factor is that biomass-based power generation for off-grid rural enterprises and small communities is considered by key government agencies as an appropriate and necessary alternative, over the long-term, to diesel-based power systems.

\section{Biomass Resources in Target Markets}

CPC's SMB system can be adapted to a variety of feedstocks as dictated by the specific target market for electrical and/or thermal energy. In the case of Indonesia, CPC's target markets for its SMB system are thousands of unelectrified plantation communities that house workers and staff for large palm oil and rubber plantations. The feedstock in these communities is either palm nutshells (a residue from palm oil mills) or rubber wood from harvesting of nonproductive trees. In the Philippines, CPC's initial target markets are offgrid communities located in regions where there is an abundance of coconut shells and corn cobs. In Brazil, CPC has identified markets in the Amazon basin and northeast regions where wood scraps and sawdust from 
small riverside sawmills, and nut shells (primarily ouricury and babasol) from local oil mills are plentiful local waste resources in thousands of communities.

The supply of relatively small quantities of feedstock required by a community-based rural electric service company to operate one of CPC's SMB systems is not considered a problem for the following reasons.

- Only those communities with a secure, long-term supply of feedstock will be selected as potential users of CPC biopower systems.

- Given the extremely large number of unelectrified communities already identified by CPC in Indonesia, the Philippines, and Brazil, there is an immense and growing pool of potential communities and customers.

- The relatively small amount of power required each day $(\sim 300 \mathrm{kWh} @ \sim 20 \mathrm{~kW}$ peak) by communities in CPC's target markets requires a correspondingly small supply of feedstock ( $\sim 300 \mathrm{~kg} /$ day/ community).

$\underline{\text { Characteristics of Feedstocks in Target Countries and Markets }}$

\section{Indonesia}

Indonesia is the world's second-largest producer of palm nut oil (more than 5 million tons/year from more than 200 mills) and a producer of more than 2 million tons of dry rubber and 60 million tons of rubber wood per year. Most production is located in CPC's target markets for the SMB system, so the selection of palm nut shells and nonproductive rubber wood as the initial feedstocks was straightforward. Furthermore, CPC's joint venture partner, the Bakrie Group, is Indonesia's largest owner/operator of palm oil and rubber plantations and has just announced the startup of a \$1 billion, 70,000-hectare palm oil plantation in Kalimantan.

CPC's field visits to both palm oil and rubber plantations in Sumatra and Kalimantan uncovered a strong willingness of the owners to supply the relatively small quantities of these residues to local communities to generate electricity. In virtually all cases, use of these residues by local communities was welcomed by the mill owners because it meant a higher quality of life for their employees (who live in the largely unelectrified communities) and an increase in the consumption of waste products, thus reducing the burden of disposal.

\section{The Philippines}

The Philippines has an abundant and varied supply of biomass resources that include crop residues, forest residues, and agro-industrial wastes. The most common and available residues for power generation and thermal processing are bagasse, rice husks, and coconut shells and husks. Wood and wood waste are the largest sources of fuel for home cooking; $61 \%$ of the total population and $84 \%$ of rural population cook with fuel wood. Countrywide, the largest quantities of biomass residues come from three sources: sugarcane (24 million tons/year), coconut (12 million tons/year), and rice (11 million tons/year).

Based on field visits to various regions and assessments of biomass resources, $\mathrm{CPC}$ has determined that the initial demonstration project will demonstrate the use of two agricultural residues: coconut shells and corn cobs. In both cases the supply of the feedstocks will be from the residue of the communities' commercial activities that produce corn and coconut oil. 
As a result of CPC's field mission to Brazil (August 1998), five significant markets for SMB systems in the 10 - to $25-\mathrm{kW}$ range - including applications for village power, small sawmills and associated communities, small agricultural cooperatives, and a variety of rural industries in the Amazon Basin - were identified. Biomass resources associated with these applications include wood scraps and sawdust residues from sawmills and residues from agricultural crops such as palm oil and cacao.

\section{CPC's SMB System Design}

The CPC SMB gasifier design is based on a thorough knowledge of the thermodynamics and kinetics of pyrolysis and charcoal gasification reactions, as well as 25 years experience with many kinds of gasifiers. The new CPC gasifier has been designed using the following parameters:

- Maximum superficial velocity (SV) in pyrolysis zone of $1 \mathrm{~m} / \mathrm{s}$

- Fuel consumption of $10 \mathrm{~kg} / \mathrm{h}$ fuel (dry, ash free basis, DAF)

- Fuel velocity in pyrolysis zone $10 \mathrm{~cm} / \mathrm{min}$ for woody biomass, $3 \mathrm{~cm} / \mathrm{min}$ for densified biomass

- Gas production $=25 \mathrm{~m} 3 / \mathrm{h}$

- Energy content of gas @ $5 \mathrm{MJ} / \mathrm{m} 3=125 \mathrm{MJ} / \mathrm{h}$

- Heat content/cooling load of gas (primarily N2) at $1000^{\circ} \mathrm{C}=1.3 \mathrm{MJ} / \mathrm{m} 3 \Rightarrow 32.5 \mathrm{MJ}$

- Gasifier efficiency $=$ heat in gas/heat in fuel $=125 / 180=70 \%$

- Gasification Air/Fuel (A/F) ratio - $1.5 \mathrm{~kg} / \mathrm{kg}$, DAF fuel basis

- Total A/F ratio 6.0, DAF basis

- Pyrolytic gasifier diameter $10 \mathrm{~cm}$

- Charcoal gasifier diameter $20 \mathrm{~cm}$.

\section{Description of CPC's SMB System}

The CPC system employs a downdraft gasifier coupled to a spark ICE generator set. The gasifier design incorporates features that result in high levels of carbon conversion with low tar production. These design and operating features produce an ash with physical properties that make it easier to separate from the gas stream. The CPC SMB system uses a dry gas cleanup technology and operation principles that prevent formation of liquid condensates. CPC's prototype SMB is self-contained on a flat bed trailer having a footprint of $5 \mathrm{ft} \times 8$ $\mathrm{ft}$.

The CPC gasifier incorporates a flaming pyrolysis tube that generates charcoal centered in a larger plenum chamber, very well insulated at the bottom. A unique system of controlled injection of air for the final charcoal gasification process contributes to low tar and ash agglomeration. Agglomerated ash is automatically removed through a sealed opening in the base. Fuel is automatically fed to the gasifier. Figure 3 provides a simplified layout of CPC's SMB prototype system as of September 1999. 


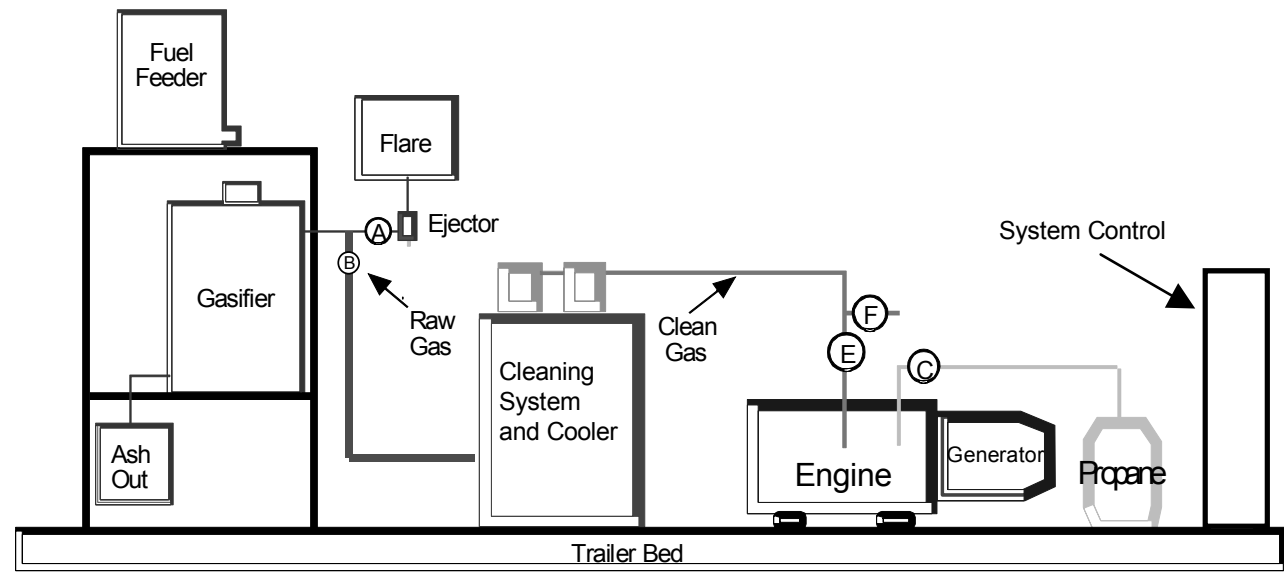

Figure 3. CPC's SMB Prototype Components

\section{Future Development}

In Phase 2, through collaboration with SR, CPC will use its new bioenergy development facility in Denver, Colorado, to prepare a pre-commercial SMB system for a series of field trails in the Philippines, where both electrical and thermal energy will be provided to off-grid communities and rural enterprises.

In cooperation with SR, CPC will continue a long-term program to develop and supply a family of field-proven and commercially viable SMBsystems to meet the growing global need for small, environmentally friendly, reliable, easily transportable and fully automated turnkey biopower systems. 


\title{
Energy and Environmental Research Center
}

\author{
Subcontractor: \\ Energy and Environmental Research Center \\ University of North Dakota \\ P.O. Box 9018 \\ Grand Forks, ND 58202 \\ Contracting Party: \\ Sandia National Laboratories \\ Subcontract Title: \\ "Small Modular Biopower Project" \\ Subcontract No.: \\ SNL BC-0002C \\ Period of Performance: \\ 4 Jun 1998 through 30 Nov 1999 \\ Subcontract Contact: \\ Dr. Michael Mann, Tel. (701) 777-5193
}

\section{Introduction}

The Energy \& Environmental Research Center (EERC) and its partners, King Coal Furnace Corporation and KJ Schwartz Engineering of Bismarck, North Dakota, have completed the preliminary design and feasibility of a modular fluid-bed biocombustor, which uses a bubbling fluid bed to burn biomass. Novel features of the system include the use of a thermal fluid for the in-bed and convective pass heat transfer, a new and novel steam engine to generate electricity, a combination biomass feed/drying system, and a modular package system developed by King Coal through its current stoker-fired business. The thermal fluid system will utilize Syltherm (polydimethyl-siloxane) to transfer the heat generated from the primary combustion system to a remote kettle boiler. By removing pressure parts from the boiler, manufacturing and operation become less costly, safer, and more flexible. A new steam engine being developed by Skinner Engine Company in Erie, Pennsylvania, offers higher efficiency and lower cost than its steam turbine counterpart. Ideal features for small remote applications, such as villages in Alaska, are the steam engine's simplicity and ease of service. The combined feed system/dryer represents a significant reduction over the use of a rotary or other dryer and offers the flexibility to handle fuels with moisture contents varying from 5\% to more than $50 \%$. The approach of packaging and delivering a complete system, including buildings, has allowed King Coal to keep system costs low so that its product can compete directly against low-cost gas- and oil-fired systems.

\section{Market Assessment}

Based on an assessment of the small power market and biomass resource availability, King Coal has chosen to focus its marketing efforts on the lumber communities of the upper Midwest, including the states of Illinois, Indiana, Ohio, Michigan, Wisconsin, Minnesota, and the remote villages of Alaska. This assessment has further indicated that a 2-MW module would be an appropriate size for the upper Midwest market; $0.5 \mathrm{MW}$ is more appropriate for the Alaskan and foreign markets. Forest residues are plentiful in both markets and represent a fuel that should perform well with minimal problems in the proposed design. Therefore, forest residues are targeted as the primary fuel for the system. Longer-range plans include incorporating design options into the fluid bed to allow operation using agriculture residues and urban wastes.

\section{System Design Concept}

The modular fluid-bed biocombustor, shown schematically in Figure 4, will use a fluid bed to combust biomass. The feed to the fluid bed will be predried in a unique feed storage bin design using heat recovered from the flue gas. Removing the moisture outside of the fluid bed eliminates the need to carry that moisture through the system and significantly reduces the size of all system components. The dried fuel is conveyed to a live bottom feed hopper and from there metered to the fluid bed. The fluid bed is designed with a sparge tube-type distribution plate to allow tramp material to fall through to a bottom drain. The bed material will be 
selected based on concerns for agglomeration and the need for sulfur or chlorine capture. For most wood wastes, sulfur content is not needed, and local and inexpensive sand will be used as the bed material.

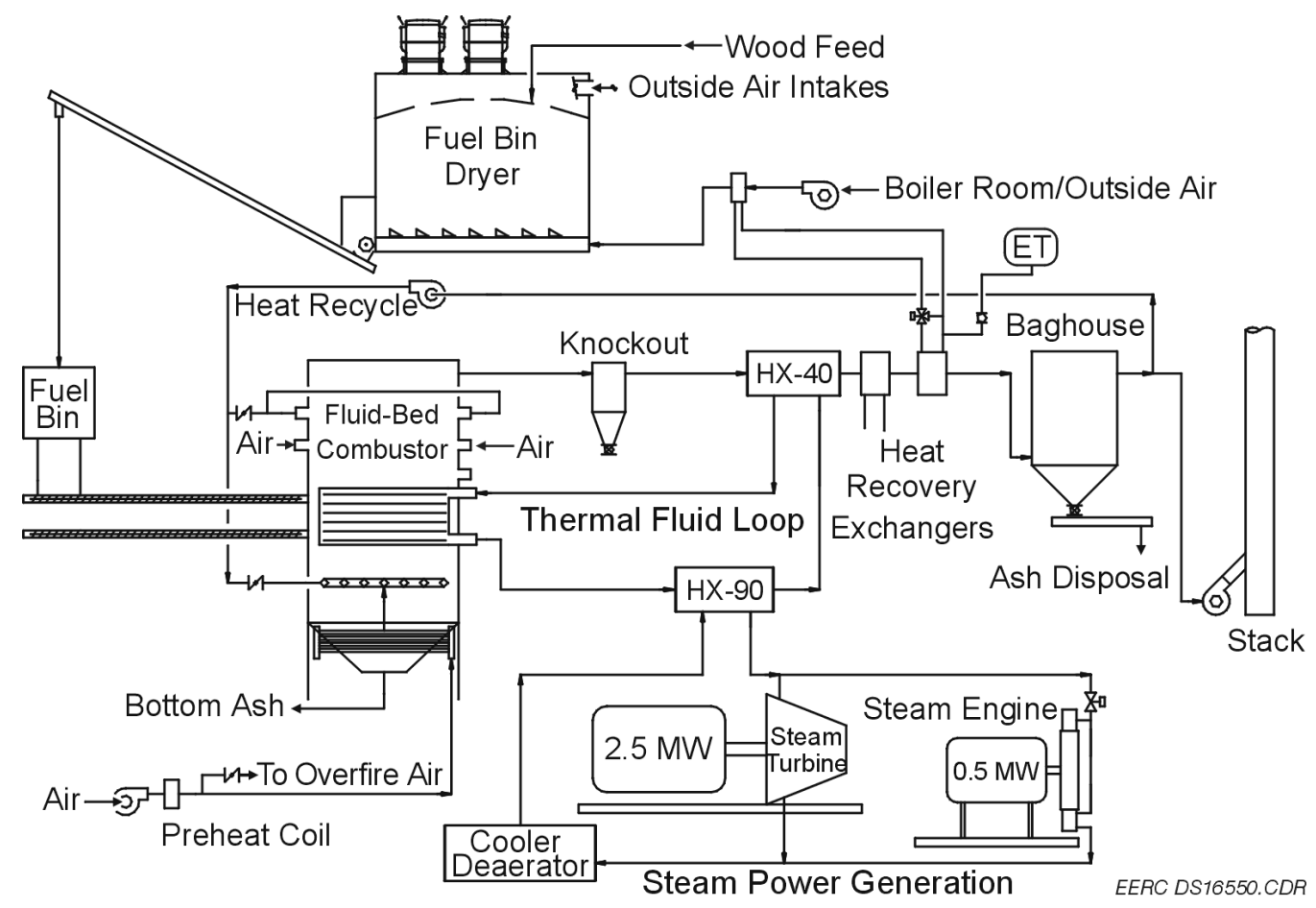

Figure 4. Modular Fluid-Bed Combuster

Preheated fluidizing air will be further heated to a design temperature of $1500^{\circ} \mathrm{F}$ by combusting the biomass in the fluid bed. Temperature and loads are controlled by varying the split of combustion air between the bed and freeboard and the amount and split of flue gas recirculation (FGR). This eliminates the need for locating heat-transfer surface in the freeboard area of the combustor. A special freeboard combustor design reduces both the required height of the combustor and the amount of ash carryover.

Heat is transferred from the bed and convective pass to heat a thermal fluid from $300^{\circ}$ to $650^{\circ} \mathrm{F}$. Syltherm, a silicon-based fluid marketed by Dow Chemical, was chosen for the thermal fluid because of its low freezing point $\left(-40^{\circ} \mathrm{F}\right)$, high boiling point $\left(750^{\circ} \mathrm{F}\right)$, and noncombustible nature. The thermal fluid then transfers its heat external to the boiler in a heat exchanger to generate steam to drive a steam engine for the smaller 0.5-MW system and a steam turbine for the larger 2-MW unit. The steam engine is an excellent choice for these applications because of its relatively high thermal efficiency, low cost, and ability to utilize low-quality (wet) steam. Its size is limited to approximately $0.5 \mathrm{MW}$; therefore, prototype testing will be performed using both a 2-MW turbine and a 0.5 -MW steam engine. This will allow a comparison of the benefits of using multiple steam engines versus a single steam turbine for the larger (2-MW) system. Multiples of the $0.5-$ or 2-MW unit will be used for electricity generation in the anticipated range of $500 \mathrm{~kW}$ to $5 \mathrm{MW}$.

Flue gases are cooled to $500^{\circ} \mathrm{F}$ by the thermal fluid heat exchanger. Particulates will be removed using a multicyclone before recovered heat from the hot flue gases is used to dry the fuel. The flue gas is cooled to approximately $120^{\circ} \mathrm{F}$ while drying the fuel from $50 \%$ to $15 \%$ moisture. The dryer makes good use of low-level heat from the flue gas that is normally wasted out the stack. 


\section{Operating Characteristics for Niche Markets}

The modular fluid bed has a simple design. King Coal has manufactured and marketed stoker systems for 20 years, with installations in schools and other public buildings, greenhouses, livestock operations, lumber mills, and other locations that lack skilled labor. In all cases, the system is designed to be operated by a janitor, maintenance worker, or other unskilled laborer. The current system will be designed using the same concept, which will allow the fluid bed to be installed in any community.

The proposed design is for a self-contained power generating system. No external electricity will be required during system operation. The system is not dependent on a power grid and can operate as a stand-alone generation system to supply power to a given facility or community. For communities such as those in Alaska where a village is currently being serviced by diesel engines, the modular fluid-bed biocombustor would replace the diesel engine as the primary power source, but would keep the diesel engine on-line as backup.

A major market for the proposed system consists of sites that require both electricity and thermal heat, either as steam or hot water. For those systems, a steam delivery system will need to be added to facilitate delivery to the thermal host. The complexity and cost of the installation of the required infrastructure will depend on the proximity of the host to the power plant and the availability of infrastructure. The delivery of the thermal load needs to be considered as a part of the preliminary plant siting.

For other applications, such as greenhouses, public buildings, agriculture processing plants, and other locations that are currently connected to the power grid and are using fossil fuels for the thermal load, the proposed system will be tied into the current infrastructure.

The cost of power in the current markets is quite variable, depending on the market site. In remote locations such as Alaska, power costs are $10 \notin$ to $40 \notin / \mathrm{kWh}$. In other locations in the lower 48 states, the cost of gas or oil as a source of heat is the driving force that makes conversion to biomass fuels attractive. Because the modular fluid-bed combustor has a broad market base, it must be able to match the price of alternative energy sources for any niche it is to fill. Generally speaking, that means electricity in the price range of $2.5 \notin$ to $7.5 \mathrm{k} / \mathrm{kWh}$. Several companies have considered, or are considering, selling "green power" at prices in this range. King Coal and its partners have estimated the breakeven power cost at approximately $6 \notin / \mathrm{kWh}$ for the proposed installation at Cass Lake, Minnesota.

\section{System Applications}

The modular fluid-bed biocombustor is designed to generate electricity alone, electricity and thermal energy, or thermal energy alone. The primary market for the system will be markets requiring either electricity alone or both electrical and thermal demands. A system range of 0.5 to $5 \mathrm{MW}$ is thought to best match the availability of the centrally located biomass for a given area and the needs for the primary users of the system.

The demand placed on the system will vary as a function of application. For example, for remote sites in Alaska, the load will have a daily peak during the day as well as a seasonal peak during the winter. Greenhouses and farming operations typically have a winter peak for heat and electricity. However, some greenhouses use special lighting to promote plant growth and have a fairly even year-round electrical demand. Other sites, such as agriculture processing plants (ethanol plant, straw board plant, etc.), will have a steady load 24 hours a day, 7 days a week, 320 to 350 days a year. The sites with the constant baseload demand are optimal locations for the proposed system. However, the modular fluid-bed biocombustor is applicable to situations with all the loads described. The steam engine by itself or in multiples is very applicable to the varying demand (load following) approach. 
The small size of the proposed system exempts it from most federal emission standards. Particulate and sulfur emissions will be regulated for systems on the larger end of the scale, with no requirements for those on the smaller end. Even though emission requirements are minimal, the modular fluid-bed biocombustor will have low emissions. Biomass typically has low sulfur, minimizing $\mathrm{SO}_{2}$ emissions. Limestone can be added to control sulfur emissions for a fuel with higher sulfur levels. The fluid bed typically generates low $\mathrm{NO}_{\mathrm{x}}$ emissions, and further reductions will be obtained with air staging and FGR. Particulate control will be met with a baghouse; $\mathrm{CO}$ levels are expected to be below $200 \mathrm{ppm}$. This should allow operation in most states and foreign countries well within the current regulatory emission levels. For states such as California with extremely low emission levels, rather expensive control systems may be required. This could preclude operation in the most sensitive areas of the country.

The prime competition for the proposed system will be electricity from the grid, steam or process heat from coal-fired stokers or gas-fired systems, and diesel generators. With regard to the use of biomass, competition will come from stoker-fired systems, gasifiers coupled to ICEs or microturbines, and sterling engines. Other competition could come from other renewables such as small hydroelectric and wind generators.

\section{Future Development}

King Coal's approach for further developing this product is to build a fully operational prototype at an industrial park in Cass Lake. This approach allows operating revenue to be generated, which will offset the cost of operating the system during the testing and evaluation phases. It also provides the opportunity to test the various developmental components in a realistic setting. The data generated on system reliability and maintainability will be needed to help market a demonstration in Alaska. The system will be equipped with both a 2-MW steam turbine and a $0.5-\mathrm{MW}$ steam engine. The steam turbine should allow for long-term stable operation and provide the flexibility to focus developmental efforts on the steam engine. In addition, long-term operation will offer the opportunity to gather design information under a variety of conditions for the dryer/feeder and the thermal fluid heat exchanges. Several iterations of these designs will likely need to be tested before determining the final specification to be included as part of the standard package. Long-term operation of these two subsystems is also crucial to demonstrating their safety. 


\title{
Niagara Mohawk Power Corporation
}

\author{
Subcontractor: Niagara Mohawk Power Corporation \\ 300 Erie Boulevard West \\ Syracuse, NY 13202 \\ Contracting Party: \\ Midwest Research Institute, National Renewable Energy Laboratory \\ "Small Modular Biopower Project" \\ Subcontract Title: \\ ACG-8-18073-05 \\ Subcontract No: \\ 30 Jun 98 through 31 Dec 98 \\ Period of Performance: \\ Dr. Peter K. Strangway, Tel. (315) 428-6532
}

\section{Background}

Niagara Mohawk Power Corporation (NMPC) will invest nearly \$2 million during 1999 to retrofit its Dunkirk Steam Station to co-fire approximately $10 \mathrm{MW}$ of biomass with coal. Co-firing has long been a goal for the Dunkirk Station owners and is seen by the new plant manager as an important added value capability as the station is transferred from NMPC to NRG in the summer of 1999. As the lead organization for the Salix Consortium, NMPC works with 20 organizations in the Northeast to scale up and demonstrate the viability of willow energy crops. This is the second leg of the NMPC program to demonstrate sustainable future energy supplies of biomass for power generation. The third leg of NMPC plans for biomass is the development of viable distributed power systems to support the grid where load growth and biomass resources converge. The proposed objective of this feasibility study was to develop a system (components and configuration) from commercially available technologies and to evaluate costs and benefits of operating the system in NMPC's service area.

In Phase 1, we proposed to explore the feasibility of biomass gasifiers for two potential near-term markets: (1) grid support for power distribution in rural locations, and (2) colocation at large-scale power generation facilities to provide $\mathrm{NO}_{\mathrm{x}}$ control and fuel flexibility. After preliminary work, the focus of the effort became grid support, or distributed generation, applications. The distributed generation systems in remote areas would be a better fit with NMPC's role in the restructured electricity market. It also appears to be a lower-risk application with very near-term applicability.

\section{Rural Service Markets for Biomass Support to Transmission and Distribution}

A distributed generation facility located at the end of the grid may be able to deliver power competitively using locally available biomass resources. In the not-too-distant future, remote customers may have to bear more of the cost of service than they do today as the electric markets are deregulated. A distributed generation system will not have to be burdened with the full charge for transmission. Biomass distributed generation may become more competitive under these circumstances, even though much cheaper power may be available at power exchanges.

The area selected by NMPC for a site-specific evaluation of the market for biomass-fueled gensets is representative of many of the rural areas bordering the Appalachian chain. In the opinion of CT Donovan Associates and Tim Volk, State University of New York Environmental Services and Forestry, the volume of resources in this region can be replicated in many areas of Pennsylvania, New York, Vermont, New Hampshire, and Maine. In the northern tier of this region a number of biomass-fueled generating plants built during the 1970s helped establish an infrastructure for biomass energy supplies. The retirement of some of these stations is creating a situation in which fuel suppliers will need to find buyers or close their operations. This situation has created near-term opportunities to acquire fuels for new projects at very competitive prices. The opportunity to pick up the slack in business will fade as suppliers adjust to the market. 
The cost of upgrading transmission and distribution to communities served by radial feeders in the Adirondack area is $\$ 4$ to $\$ 8$ million. A generation system using local fuels would be an attractive alternative to reconducting the transmissions lines if capital requirements were the same or less, and the (levelized) COE was competitive. The use of reliable distributed generation technology would mean that the needed capacity could be added without disrupting service during construction. System reliability would improve because these rural customers could be served by two independent sources much the same way that transmission loops often provide two routes to reach the customer.

\section{Technology and Application Economics for Grid Support Applications}

Although this study discovered significant outstanding technical issues with gasification and its use with engine systems, the design and costing of a system were undertaken to understand the economics of a 5-MW biomass power plant built with currently available equipment. The power plant would be composed of the gasifier, gas turbine and generator, wood receiving facility, a stockyard, sizing equipment, a rotary wood dryer, storage silo, and a substation. The plant is assumed to be located somewhere in the Adirondack Park region within one-half mile of a distribution substation.

This plant is intended for base load duty to maximize utilization and thus lower costs. The system design began with the premise of generating a nominal $5 \mathrm{MW}_{\mathrm{e}}$ capacity. The net output of the plant turned out to be 4.27 MW after plant parasitic uses. As a base loaded plant, the capacity utilization was assumed to be $90 \%$ or better.

The Primenergy gasifier is used as the basis of the system. This system requires that the wood feed have a moisture content (MC) of $20 \%$ or less. Because a large portion of the wood supply will be whole green chips and bark, a dryer is required. A gas turbine generator was chosen over a spark ignition reciprocating engine generator because it has lower capital and operating costs. A Solar Turbine's Taurus 60, rated at 52,000 kW ISO base load, was chosen as a representative model. To complete the plant, a substation is required to step up the voltage to tie into the distribution system. Total capital requirements are an estimated $\$ 15$ million.

Table 10.

\begin{tabular}{|l|l|}
\hline Gross output & $5.2 \mathrm{MW}$ \\
\hline Net output & $4.27 \mathrm{MW}$ \\
\hline Annual net output & $33,633 \mathrm{MWh}$ \\
\hline Capacity utilization & $90 \%$ \\
\hline Annual operating hours & 7884 \\
\hline Fuel & Wood residues \\
\hline Fuel consumption & 103,000 green tons/yr \\
\hline
\end{tabular}

At this point, NMPC realized that building a modular 5-MW system for stand-alone electricity service from today's off-the-shelf equipment would not be cost competitive with the line upgrade alternative. Given the significant technical issues with gasifiers of that capacity and their coupling with a turbine or reciprocating engine, a successful demonstration of this scale of application within the next 5 years seemed unlikely. A major technical development and demonstration effort would have to be mounted to build a system in the near term that would satisfy NMPC standards for service. 
Despite this conclusion, a financial analysis was conducted to complete the feasibility study. A levelized revenue requirement calculation was performed for the base case (building in the near term with currently available equipment with current wood prices). Several scenarios were run from the base case to illustrate the impact of capacity utilization, wood cost, and total capital requirements. Finally, an analysis was performed to establish cost and performance goals for future systems. A best case system was developed by optimistically cutting costs and improving performance in every area available.

The calculated COE for the base case is $16.28 \notin / \mathrm{kWh}$, mostly because of the high costs of handling, sizing, and drying the wood. Because of the labor required and the maintenance of the equipment, the O\&M costs comprise more than half the COE.

The COE for the future system design is $8.2 \phi / \mathrm{kWh}$ with $\$ 14.00 /$ green ton wood, or $5.9 \notin$ with zero cost wood. A capital investment of $\$ 10.5$ million is required. This is considerably closer to providing an alternative to the line upgrade option. However, capital requirements still exceed the transmission line upgrade, and the COE exceeds, albeit slightly, the rates established for the Adirondack Park region. Lastly, achieving this level of cost with the attendant expectation of higher performance and high reliability and availability is likely to be a large undertaking.

\section{Conclusions}

NMPC remains very interested in the development of an advanced, cost-effective biomass modular generation technology that uses local resources. The cost of upgrading radial feeders in rural, environmentally sensitive areas will require significant company investment during the next 10 years. However, we have concluded that biomass gasification systems are not technically or economically ready to provide a viable alternative to reconducting. The efficiency of the gasifiers must be improved and their reliability demonstrated before these systems can be considered ready for service. Much of the required work is underway, and we hope that DOE can continue to support these efforts.

Although NMPC is not prepared to assume a primary R\&D role at this juncture, we would be open to partnering with a technology developer and others when the technology is ready for a pre-commercial demonstration. 


\title{
Reflective Energies
}

\author{
Subcontractor: $\quad$ Reflective Energies \\ 22922 Tiagua \\ Mission Viejo, CA 92692-1433 \\ Contracting Party: \\ Midwest Research Institute, National Renewable Energy Laboratory \\ Subcontract Title: \\ "Small Modular Biopower Project" \\ Subcontract No.: \\ NREL ACG-8-18073-03 \\ Period of Performance: $\quad 6$ Jun 98 through 31 Dec 99 \\ Subcontract Contact: $\quad$ Edan Prabhu, Tel. (714) 380-4899
}

\section{The Flex-Microturbine, ${ }^{\mathrm{TM}}$ Running on Low-Pressure, Low-Energy Gases}

Reflective Energies is developing a new business that will convert enormous quantities of previously unusable waste into electricity at very low cost. The key technology for the new business is a small, reliable, microturbine electric power plant, the Flex-Microturbine. ${ }^{\mathrm{TM}}$ The Flex-Microturbine ${ }^{\mathrm{TM}}$ will be able to run on fuel gases that are today considered too low in pressure or energy content to produce electric power. It will be able to tap many sources of renewable energy. Flex-Microturbines ${ }^{\mathrm{TM}}$ will accept a wide range of low-grade fuel gases while producing lower emissions than "traditional" microturbines. The Flex-Microturbine ${ }^{\mathrm{TM}}$ will run on the waste gas now flared from landfill operations, from animal waste, and on low-energy gas from the gasification of biomass in addition to waste gases from petroleum and coal production operations. The EPA considers each of these streams a major environmental hazard and has specific programs for mitigating emissions from each such operation.

Reflective Energies is partnered with Capstone Turbine Corporation, maker of the world's first commercial microturbine power plant and the first to obtain UL approval for the entire power plant. The FlexMicroturbine $^{\mathrm{TM}}$ will be adapted from the commercial Capstone MicroTurbine ${ }^{\mathrm{TM}}$ line, and will be produced, marketed, and serviced by Capstone.

The Flex-Microturbine ${ }^{\mathrm{TM}}$ will create markets not currently available to other microturbines, which require pressurized, high-Btu fuel or expensive fuel gas compressors. By using low-grade fuel that is now going to waste, these plants will produce electricity at significantly lower costs than larger plants. They would also provide major environmental and social benefits, converting damaging waste into electricity. In many cases, the environmental or renewable energy benefits will qualify for subsidies from governments and multilateral institutions pledged to support renewable energy and to combat global warming.

Flex-Microturbines ${ }^{\mathrm{TM}}$ will be also run on low-Btu biomass gas from waste wood and crop residues. It will run on fuels well below $100 \mathrm{Btu} / \mathrm{scf}$ with no other fuel present. These are important fuels for many developing countries with desperate shortages of power and large quantities of underutilized or destroyed biomass.

Portable plants coupled to small wood gasifiers will be developed and fitted onto flatbed trailers. Instead of moving the fuel to the plant, these plants will be moved from site to site to consume local fuel. This will be especially valuable in the western United States where decades of dying trees and brush pose threats of catastrophic fires, and where huge quantities of unwanted crop and orchard residues are mounting.

In addition to its enormous renewable energy applications, the Flex-Microturbine ${ }^{\mathrm{TM}}$ will also be the practical low-cost technology for low-pressure natural gas. The ultra-low emissions and the elimination of the fuel for gas compressors will offer compelling advantages over traditional microturbines. Whereas emissions limit the use of certain natural gas engines, the Flex-Microturbine ${ }^{\mathrm{TM}}$ will meet the most stringent emissions requirements anywhere. 
The Flex-Microturbine ${ }^{\mathrm{TM}}$ creates a fundamental increase in the usefulness of microturbines, and will enhance the quality of life for people all over the world.

\section{The Market}

The world market for the Flex-Microturbine, ${ }^{\text {TM }}$ using only fuels presently wasted, is several hundred thousand megawatts. The projected annual sales for the Flex-Microturbine ${ }^{\mathrm{TM}}$ are presented in Table 11. The figures assume that only $1 \%$ of the total potential market will be achieved each year.

Table 11. The Flex-Microturbine ${ }^{\mathrm{TM}}$ Market Potential

\begin{tabular}{|c|c|c|c|c|c|}
\hline Market & Fuel Source & Potential MW & No. of Units & Units per Year & Revenue @ \$400/kW \\
\hline & & & $100 \%$ of market & $1 \%$ of market/yr & Annual Gross Rev. \\
\hline \multirow[t]{5}{*}{ California } & Wood/crop residue & 1000 & 33000 & 330 & 4000000 \\
\hline & Landfill Gas & 500 & 16500 & 165 & 2000000 \\
\hline & Animal Manure & 100 & 3300 & 33 & 400000 \\
\hline & Other Waste Gas & 1000 & 33000 & 330 & 4000000 \\
\hline & Total Calif. & 2600 & 85800 & 858 & 10400000 \\
\hline \multirow[t]{5}{*}{ U.S. } & Wood/crop residue & 10000 & 330000 & 3300 & 40000000 \\
\hline & Landfill Gas & 10000 & 330000 & 3300 & 40000000 \\
\hline & Animal Manure & 1000 & 33000 & 330 & 4000000 \\
\hline & Other Waste Gas & 10000 & 330000 & 3300 & 40000000 \\
\hline & Total U.S. & 31000 & 1023000 & 10230 & 124000000 \\
\hline \multirow[t]{5}{*}{ Worldwide } & Wood/crop residue & 100000 & 3300000 & 33000 & 400000000 \\
\hline & Landfill Gas & 25000 & 825000 & 8250 & 100000000 \\
\hline & Animal Manure & 20000 & 860000 & 6600 & 80000000 \\
\hline & Other Waste Gas & 100000 & 3300000 & 33000 & 400000000 \\
\hline & Total Worldwide & 245000 & 8085000 & 80850 & 980000000 \\
\hline
\end{tabular}

\section{Market Drivers}

There are several reasons why customers will select the Flex-Microturbine ${ }^{\mathrm{TM}}$ to generate electricity. Where fuel is a free by-product, electricity will simply be sold for a profit. Renewable energy incentives will enhance the economics. Some customers will even run the Flex-Microturbine ${ }^{\mathrm{TM}}$ on low-pressure natural gas to offset high retail electricity costs and to enhance the security of electric supply. President Clinton's Executive Order calling for a threefold increase in bioenergy by 2010 will accelerate the market. 
Figure 5 compares the cost of generating electricity from the Flex-Microturbine ${ }^{\mathrm{TM}}$ to the cost of wholesale and retail electricity. For low-grade fuel applications the Flex-Microturbine ${ }^{\mathrm{TM}}$ beats bulk power prices. For niche applications, the Flex-Microturbine ${ }^{\mathrm{TM}}$ beats retail power prices even with natural gas as the fuel. Figure 5 does not take credit for any renewable energy subsidies, buydowns, green power portfolio standards, and pricing. Such subsidies, available in the United States and worldwide, will further enhance the economics.

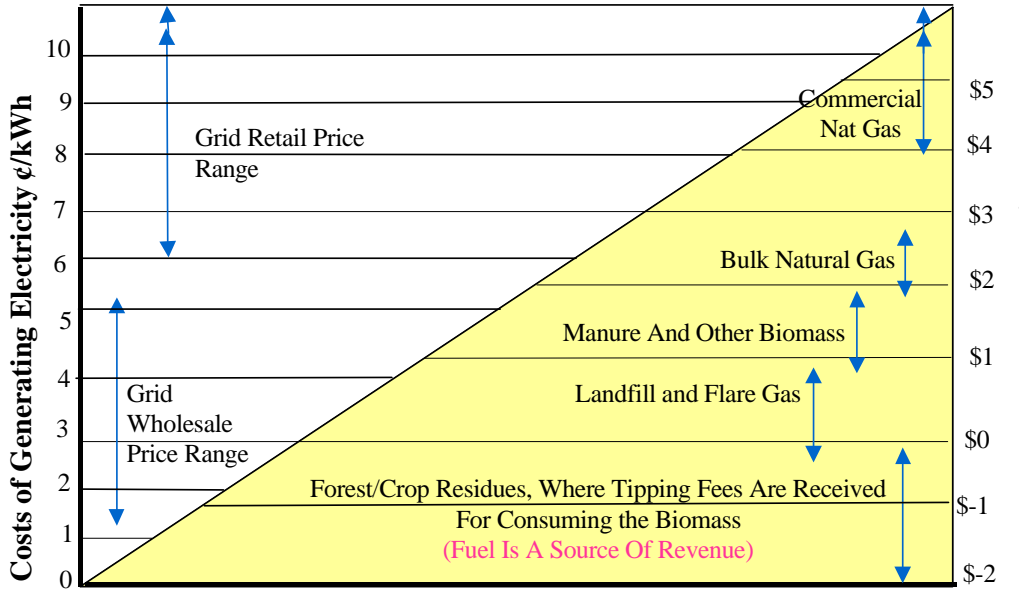

Figure 5. Microturbine generating costs for various fuels compared to traditional generation costs

Even without subsidies, the capital payback period for many of the applications will be between one and three years. This payback will be quickest where fuel is essentially free for the taking, such as in numerous landfill operations today, or where labor is inexpensive.

\section{Current Status and Plans}

The critical technical development work is now complete, supported by important funding from DOE and NREL. Successful safety testing of the new concept performed at the University of California Combustion Laboratory in Irvine. Key partnerships have been established. A development agreement with the EERC, Grand Forks, is underway. Funds for demonstration testing are expected from the DOE and the State of California's PIER program. The first demonstration units are expected in early 2000 with commercial units available in early 2001. Demonstration units will be run on "producer" gas from wood gasifiers, landfill gas, and on digester and petroleum production gases currently being flared.

\section{Business Strategy}

Following development of the Flex-Microturbine ${ }^{\mathrm{TM}}$ and hand-over of manufacture and marketing to Capstone, Reflective will focus on developing high-value, high-visibility projects for the Flex-Microturbine ${ }^{\mathrm{TM}}$ in the United States and elsewhere. There is already a strong market pull for this product, with a large backlog of potential buyers. Interested parties include DOE, the Los Angeles County Sanitation District, the California Department of Forestry, Dane County Landfill in Madison, Wisconsin, NISource, and other landfill and animal digesters around the nation. In addition, the World Bank, the Global Environment Facility, United States Agency for International Development, the United Nations Development Program, the International Finance Corporation, and others have expressed interest in such a dependable renewable energy system that is easily installed, uses local fuel, and creates local jobs. As in the United States, Reflective will develop high-visibility international projects, seeding the market for rapid growth. 


\section{STM Corporation}

\author{
Subcontractor: $\quad$ STM Corporation \\ 275 Metty Drive \\ Ann Arbor, MI 48103 \\ Contracting Party: \\ Subcontract Title: \\ Subcontract No.: \\ Period of Performance: \\ Subcontract Contact: \\ Sandia National Laboratories \\ "Small Modular Biopower Project" \\ SNL BC-0002A \\ 19 May 1998 to 30 Nov 1999 \\ Dr. Benjamin Ziph, Tel. (834) 995-1755
}

\section{Introduction}

Pursuant to SNL's contract \#BC-0002A, STM Corporation has been developing an SMB system based on STM's 25-kW Stirling-cycle engine: the STM4-120. The Stirling-cycle engine is externally heated and thus requires merely a sufficiently hot flow of combustion gases through its heat exchanger to produce power. A Stirling-based biopower system can then be implemented simply by directing the gaseous products of the combustion of solid biomass fuel through the heat exchanger of the engine, in contrast with ICE-based systems that require the solid biomass fuel to first be converted into cool and clean gaseous fuel.

The objectives of Phase 1 have been to develop technical and business strategies for incorporating the STM 4-120 engine with a solid biomass combustion system, into an SMB system and to commercially introduce this system into suitable markets. The approach to the Phase 1 study was based on the recognition that commercial introduction will be strongly facilitated by employing a developed engine that will be mass-produced for a number of applications.

STM engaged the Antares Group to conduct a market assessment study and a biomass resource assessment study. Inputs from these studies were used to design a complete biopower system made up of the STM 4-120 Stirling engine close-coupled to a commercial updraft sawdust gasifier and equipped with an induction generator to produce grid-connected electric power. The design was then used to assess the performance, costs, safety, and environmental impacts of the system. Finally, all this information was taken into consideration in developing a preliminary business plan and commercialization strategy.

\section{Potential Markets}

The domestic market potential was based on the estimated amount of sawdust available. Previous analyses showed that sawdust presents the most viable biomass feedstock for the BioStirling system because of its abundance and physical characteristics. Sawdust is generated by both primary and secondary wood processing facilities. Residue that is disposed of at no higher value to the mill was considered to be available for use as feedstock. This category includes residue that the mill gives away, pays to have removed, stockpiles onsite, incinerates onsite, landfills, or scraps in any other way. The market is the number of STM units that can be supported annually multiplied by available sawdust. The total revenue was arrived at by assuming STM captured $100 \%$ of this market. The price per $25-\mathrm{kW}$ unit was assumed to be $\$ 40,000$, and each unit needs to be fueled by 457 tons of sawdust per year. For the primary mills market, the analysis shows that STM has the potential to sell 4040 units and collect $\$ 161$ million in revenue. For the secondary mills market, STM has the potential to sell 1258 units and collect $\$ 50$ million in revenue, across the United States.

Table 12 outlines some key assumptions: 
Table 12. Summary of Domestic Market Potential Assumptions

\begin{tabular}{|l|l|}
\hline \multicolumn{1}{|c|}{ Variable } & Value \\
\hline System Size & $25 \mathrm{kWe}$ \\
\hline System Cost & $\$ 1,600 / \mathrm{kW}$ \\
\hline System Efficiency (electrical) & $29,246 \mathrm{Btu} / \mathrm{kWh}$ \\
\hline Operating Hours & $7000 \mathrm{~h} / \mathrm{yr}$ \\
\hline Fuel HHV (@ 30\% MC) & 5600 \\
\hline Sawdust Required/Unit & 457 tons/yr \\
\hline $\begin{array}{l}\text { Secondary Mill Residues/ } \\
\text { Primary Mill Residues }\end{array}$ & 0.31 ton/ton \\
\hline Avail. Sawdust/Total Avail. Residues & 0.39 ton/ton \\
\hline
\end{tabular}

A first approximation was made of the international market potential for each country analyzed in this report. Results showed that if it captures $100 \%$ of the market, STM has the potential to sell 9371 units and collect $\$ 375$ million in revenue across the 21 countries in this analysis.

The economic benefit of the BioStirling system to the end user will be the key to its success. This will rely on demonstrating the value of producing on-site electricity/heat and the waste disposal avoidance benefits of this system. A simple tool was developed that provides some perspective on the market conditions necessary to make the BioStirling system attractive. Table 13 summarizes the analysis in a cross-tabulated matrix.

Table 13. STM SYSTEM BENEFITS (cents/kWh) Accrued through Avoided Residue Disposal Costs and Heating Fuel Offsets

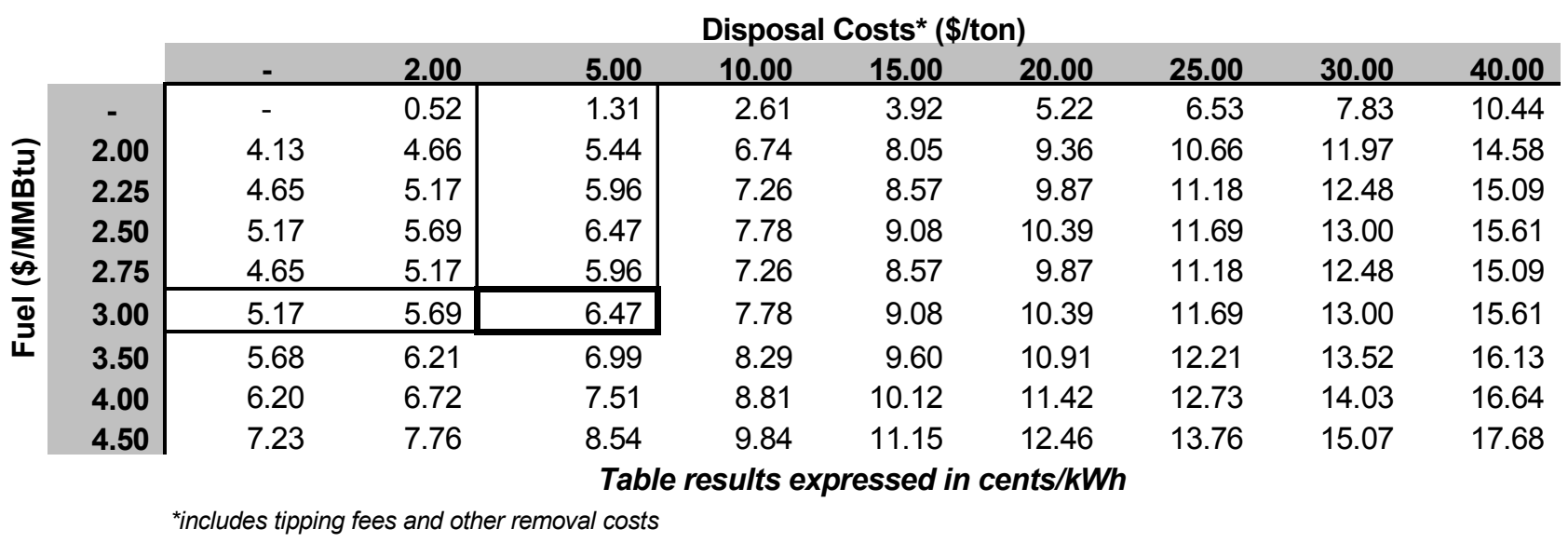

The analysis relies on the following assumptions:

- Overall thermal efficiency of the BioStirling system is $82 \%$.

- Heating fuel is displaced at $\$ 2.00-\$ 4.50 / \mathrm{MMBtu}$ via heat recovery.

- Tipping fees paid for waste wood removal range from $\$ 0.00$ to $\$ 40.00 /$ ton. 
Under these assumptions, the value of offsetting tipping fees and heating fuel costs can exceed $17 \notin / \mathrm{kWh}$. The effect of this is illustrated in the following example.

A facility is currently paying $\$ 5 /$ ton disposal costs for waste wood. The facility will also be able to use the waste heat from the BioStirling system and currently pays $\$ 3.00 / \mathrm{MMBtu}$ for heating fuel. Therefore, the avoided cost benefit of the STM system is $6.5 \mathrm{c} / \mathrm{kWh}$. The significance of this benefit is illustrated as follows:

Sawmill's current electricity costs as purchased from the grid

Less BioStirling electricity generation (capital plus O\&M, fuel is free)

Savings in electricity cost

Benefit of avoiding heat and disposal costs

Net benefit realized through BioStirling utilization

Annual Generation

Net Annual Benefit (rounded)

$$
\begin{array}{r}
5.5 \notin / \mathrm{kWh} \\
-4.8 \notin / \mathrm{kWh} \\
+0.7 \notin / \mathrm{kWh} \\
6.5 \notin / \mathrm{kWh} \\
7.2 \varnothing / \mathrm{kWh} \\
175,200 \mathrm{kWh} \\
\hline \mathbf{\$ 1 2 , 6 0 0}
\end{array}
$$

The net annual benefit appears attractive and translates into a 3-year simple payback on the investment. This analysis also suggests that the benefits of avoiding disposal and heating fuel costs will far outweigh the benefits of on-site electrical generation unless the facility is paying very high electricity costs.

Two other considerations enhance the market projection but are not included in the reference case:

- Some states grant a $\$ 5 /$ ton credit for the conversion of sawdust into an "economically valuable product," which can include electricity. This credit would add to the overall economic benefit of an end user.

- The system described herein presumes sawdust as the feedstock of choice. Not included in the market projections is that the BioStirling system may also employ, without change, other compatible feedstocks - primarily agricultural wastes.

\section{System Design}

Figure 6 shows a schematic of the biopower system. The biomass feedstock is combusted in two stages: The first is a sub-stoichiometric, sub-atmospheric gasification using Chiptec Wood Energy Systems' C-1 updraft sawdust gasifier. The second stage - complete combustion of the gas from the first stage - takes place in a continuous combustor equipped with a jet pump flow inducer. A combustion blower supplies the secondary air to the combustor. The secondary air creates suction at the jet pump throat to induce atmospheric airflow into the gasifier and producer gas flow out through the ash separator and to the secondary combustor where it burns with the secondary air. The combustion gases then flow through the engine heat exchanger, give up its heat to the engine, and are exhausted or delivered to an application-specific consumer heat load. Between the gasifier and the secondary combustor are disposed a cyclone fly-ash separator and a bypass system that is activated only upon startup and shutdown of the system. The engine drives an induction generator to produce grid-connected electric power.

The technical specifications of the system are summarized in Table 14. 


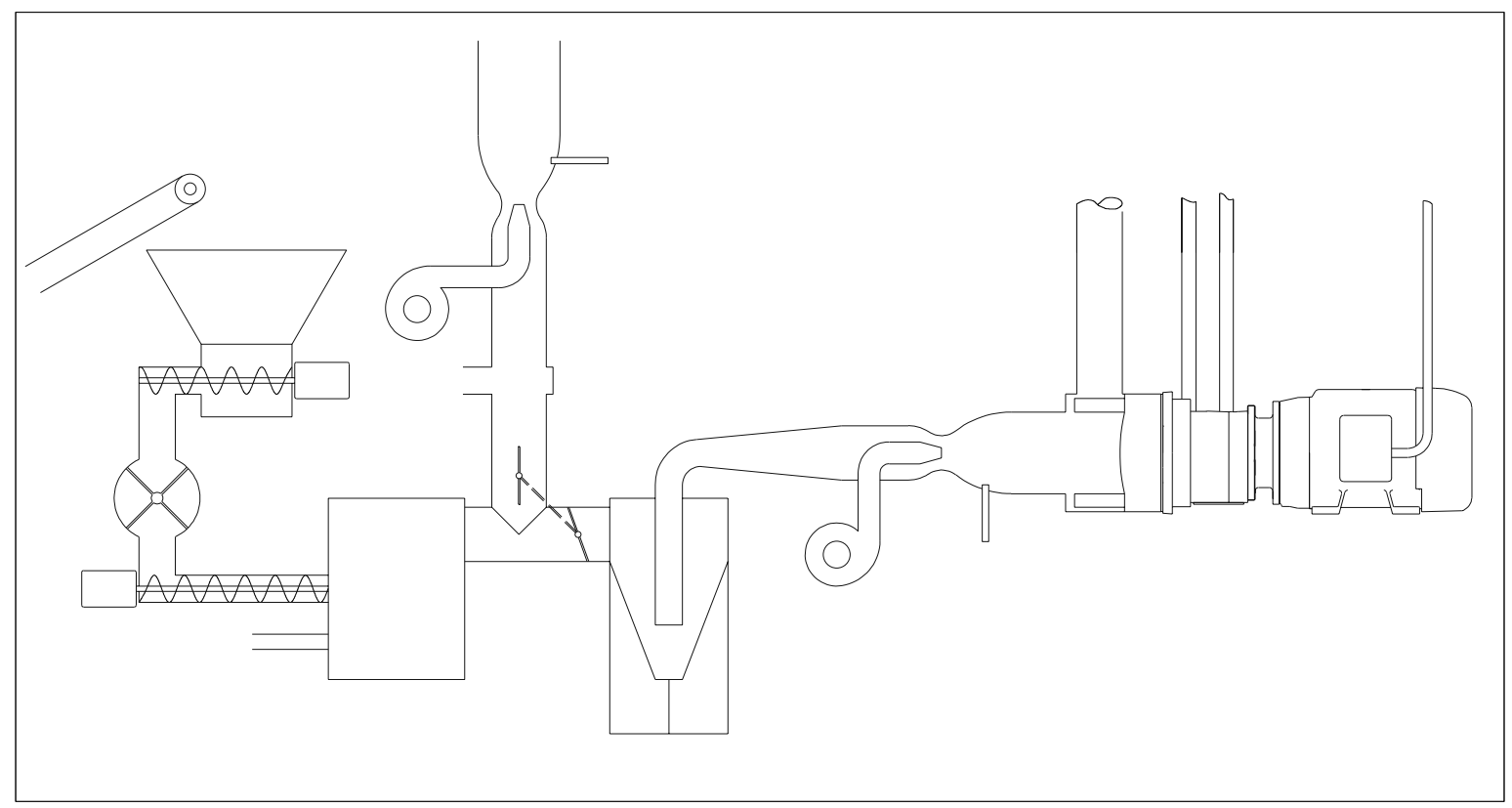

Figure 6. BioStirling System Schematic

Table 14. BioStirling System Specifications

\begin{tabular}{|l|l|}
\hline Primary feedstock & Sawdust \\
\hline Feedstock consumption & $59 \mathrm{~kg} / \mathrm{h}$ \\
\hline Air flow Primary & $24 \mathrm{~g} / \mathrm{s}$ \\
\hline \multicolumn{1}{|c|}{ Secondary } & $108 \mathrm{~g} / \mathrm{s}$ \\
\hline \multicolumn{1}{|c|}{ Total } & $132 \mathrm{~g} / \mathrm{s}$ \\
\hline Electric power & $25 \mathrm{kWe}$ \\
\hline Heat to consumer & $140 \mathrm{~kW}$ th at $813^{\circ} \mathrm{C}$ \\
\hline Coolant heat & $41 \mathrm{kWth}$ at $60^{\circ} \mathrm{C}$ \\
\hline Energy utilization efficiency & $86.5 \%$ \\
\hline Exhaust heat & $29 \mathrm{kWth}$ at $200^{\circ} \mathrm{C}$ \\
\hline Installation size $(\mathrm{L} \times \mathrm{W} \times \mathrm{H})$ & $5.66 \times 2.87 \times 3.66 \mathrm{~m}$ \\
\hline Emission indexes $(\mathrm{g} / \mathrm{kg}) \mathrm{CO}$ & 1 \\
\hline \multicolumn{1}{|c|}{$\mathrm{NO}_{\mathrm{x}}$} & 2.5 \\
\hline Design life & $50,000 \mathrm{~h}$ \\
\hline
\end{tabular}

A layout of the system is shown in Figure 7.

The BioStirling design concept addresses the following technical issues:

- Fouling and corrosion

- Safety and environmental pollution

- Durability and economical operation. 

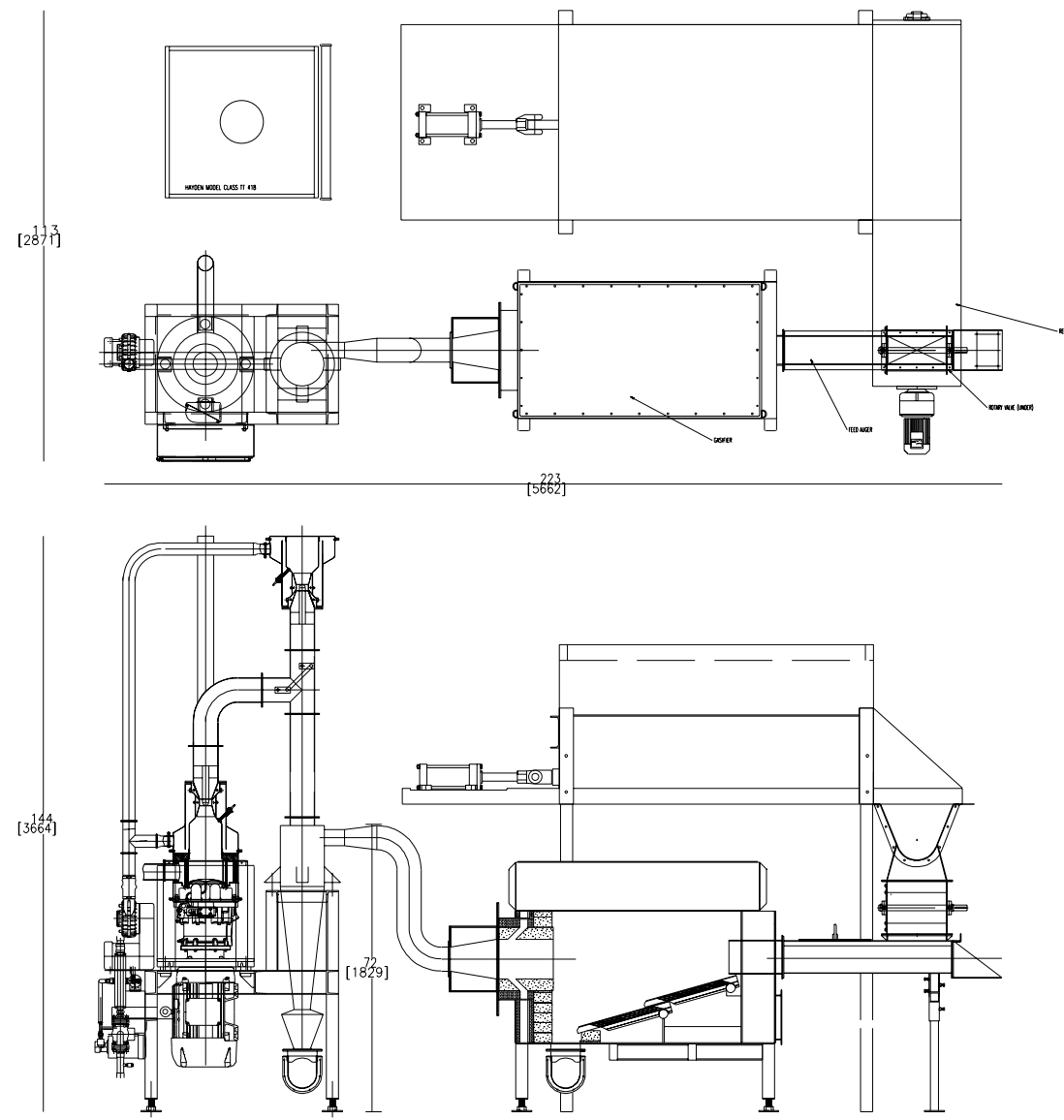

Figure 7. BioStirling System Layout

The primary design decisions reflected in the system design are:

- Separating the combustion into a first gasification stage, at about $700^{\circ} \mathrm{C}$-below the limit where alkali vapors form and ash fuses, and a second, close-coupled, lean combustion stage so tars in the gas from the first stage never condense. This eliminates the need for scrubbing the gas and the associated problem of having to dispose of liquid effluent. A metallic cyclone fly-ash separator is deployed in the $700^{\circ} \mathrm{C}$ stream between the two stages. The only disposable waste generated by the system is a small amount of dry ash.

- The air delivery system where the secondary air supply is used to induce the primary air and gas flow maintains the gasifier and gas handling system at sub-atmospheric pressure and greatly enhances the safety of the system. At the same time, the air blower only handles cold air, which reduces cost and enhances the durability and performance of the system.

- Neither the primary nor the secondary air is preheated. This reduces the cost, maintenance requirement, and parasitic losses but requires about twice the specific fuel consumption compared to a system using preheated air. This design decision, in essence, makes the system a cogeneration plant (and a waste incinerator) and reflects the results of the market analysis, which suggests that the benefits of avoiding disposal and heating fuel costs will far outweigh the benefits of on-site electrical generation. 


\section{Future Development}

The BioStirling system will be introduced to the market via selective demonstration programs involving commercial organizations or parties affiliated with commercial entities that need the system and that are known high-exposure participants in the biomass market.

- A joint venture with a major industrial partner is now in the process of being formed.

- The bulk of marketing (sales-service-distribution) will be the responsibility of the industrial partner.

- STM shall remain the technology provider to the joint venture and assume some manufacturing functions for the production of Stirling-specific components.

- Future development and deployment funding is envisioned from a variety of sources, depending on the market and dominant pacing items involved.

- Internal R\&D funds from the joint venture.

- Agencies with dedicated biomass programs resolving environmental concerns connected to biomass.

- Multinational aid and funding organizations.

- Revenues from commercial sales. 


\section{Sunpower, Inc.}

\begin{tabular}{|c|c|}
\hline Subcontractor: & $\begin{array}{l}\text { Sunpower, Inc. } \\
182 \text { Mill Street } \\
\text { Athens, OH } 45701\end{array}$ \\
\hline Contracting Party: & $\begin{array}{l}\text { Midwest Research Institute, National Renewable Energy Laboratory } \\
\text { Division }\end{array}$ \\
\hline Subcontract Title: & "Small Modular Biopower Project" \\
\hline Subcontract No: & ACG-8-18073-03 \\
\hline Period of Performance: & 6 Jun 98 though 30 Sep 99 \\
\hline Subcontractor contact: & $\begin{array}{l}\text { Elaine Mather, Tel. (740) 594-2221 } \\
\text { mar@ po r.com }\end{array}$ \\
\hline
\end{tabular}

\section{Introduction}

The subject of this SMB project is a system that burns biomass fuels and converts the resulting heat to electric power by means of a free-piston Stirling engine. The first systems to be commercialized through this project are designed to burn wood fuels, because at present those fuels are widely used by a large, initial target market: homeowners who burn wood for heat. Later products will be designed to burn other types of biomass fuels as they become commercially available.

The overall objective of this SMB project is to develop SMB systems that are fuel-flexible, efficient, simple to operate, whose operation has minimum negative impacts on the environment, and that provide power in the range of electrical generation sizes smaller than $20 \mathrm{~kW}$ for domestic and international markets. The Phase 1 objective was a feasibility study that includes a market assessment, resource assessment, preliminary system design, assessment of relevant environmental and safety considerations, evaluation of financial and cost issues, and preliminary business plan and commercialization strategy.

This project achieved all Phase 1 objectives with respect to the first product in a line of SMB systems. That product is a system that cogenerates as much as $1 \mathrm{~kW}$ of electrical power together with heat for water and space heating in single-family dwellings. Later products will have electrical output capacities as high as $20 \mathrm{~kW}$ for larger residential, commercial, and agricultural applications.

\section{Potential Markets}

\section{The Market}

The target market for these products is in individual residential, small commercial, and farm buildings worldwide wherever low-cost biomass fuel is abundantly available and electric power is unavailable, unreliable, or expensive. These products will be sold in three market segments: remote homes in developed countries, off-grid rural electrification in developing countries, and on-grid distributed power production worldwide.

Near-term sales opportunities for these products are in the forested territories of the higher latitudes where wood is burned extensively as a fuel. The aggregate sizes for all single-family residences in North America, Europe, and developing countries are estimated to be $\$ 200$ billion, $\$ 230$ billion, and $\$ 150$ billion, respectively. 


\section{The Biomass Fuels}

The initial models of these residential cogeneration products will burn wood pellets and fuel wood. Most wood pellets used for residential heating are made from sawdust and ground wood chips, which are waste materials from trees used to make furniture, lumber, and other products. Pellet fuels graded by The Pellet Fuels Institute must meet tests for density, dimensions, fines, chlorides, and alkali content. These physical and chemical properties are ideal for biomass combustion, but the processing that contributes these virtues also makes pellets the most expensive form of biomass fuel. Because they are densified, pellets can be profitably transported to distant markets.

Fuel wood is harvested as a fuel source rather than as lumber or for other purposes. Production is highest in the forested territories of the northern and central latitudes. The United States produces the most fuel wood in North America. Russia produces the most fuel wood in Europe, but per capita fuel wood production is much greater in the Scandinavian and Baltic countries, especially in Finland.

\section{Competing Demand for these Biomass Fuels}

The primary competing demand for these biomass fuels is residential heating. The new residential biomass cogeneration products will not change this usage for the initial target market of homeowners who already burn wood for heat. Later the market will be expanded to displace expensive and polluting residential electric and fossil fuel heat sources, which will increase the demand for biomass fuels.

\section{The Optimum Size for this Technology}

Historically, Stirling engines have been fabricated in capacities from $1 \mathrm{~W}$ to more than $1 \mathrm{MW}$. The optimum size for this technology is an economic issue relative to competing technologies for the same application, and it has not yet been determined in the marketplace. Stirling engines work by sensible heat transfer into and out of the engines, so they are believed to be most competitive as their size is reduced and their surface-to-volume ratio increases. Therefore, free-piston Stirling engines are generally believed to be most economically competitive with other technologies at power levels less than $20 \mathrm{~kW}$; this advantage is believed to increase as size is further reduced. This favors an economy of scale based on high-volume manufacturing rather than on high unit capacity.

\section{The Demand for this Type of Power}

Such a low power range has a major economic advantage over larger biopower technologies that compete with other large generating technologies in a wholesale deregulated electric power market. Residential biomass cogeneration systems can compete on the retail market where competing prices are highest. This creates opportunities for higher margins and smaller financial risks. Furthermore, avoidance of a separate heating bill also creates a large economic incentive for homeowners to convert from expensive electric heat to biomass cogeneration.

For example, for the 1 million off-grid homes in North America, the competing prices of electricity range as high as $75 \notin / \mathrm{kWh}$ or more and the primary heat source for many of these homes is wood. In North America, 15 million homes burn wood for heat, including 5 million in the Northeastern states (where homeowners pay the highest electric utility rates in North America). In addition, 9 million homes are heated by electricity.

Of the countries with the highest average household electric utility rates, all but Korea and Japan are in Europe. In Europe, too, many are heated by wood, including 1.3 million in Scandinavia, 600,000 in Austria, and 2.5 million in France. Many more homes, including 2.5 million in Scandinavia, 300,000 in Austria, and 9 million in France, are heated by electricity. 


\section{Fit of the Optimum Size to the Demand}

In middle-class, single-family residences in developed countries, the average annual electrical load for purposes other than space heating and cooling is $1 \mathrm{~kW}$. The average daily peak electrical load is $\sim 1.5 \mathrm{~kW}$ and momentary surge loads can be as great as $6 \mathrm{~kW}$ as motors in home appliances start up. The peak load exceeds $1 \mathrm{~kW}$ for only a few hours per day, however, and surge loads occur for only a few minutes per day.

Sunpower believes that the greatest home economy will be achieved by residential cogeneration systems that serve the average annual electrical load and use other sources of electrical power, such as an electrical utility grid or a battery bank and an inverter, to serve peak and surge loads. Thus, the optimum size of free-piston Stirling engines fits especially well with the average annual electrical demand of the single-family residential market.

\section{Biomass Requirement and Availability}

A 1-kW residential biomass cogeneration system for markets in northern latitudes may be designed to burn the least fuel required for the system's electric generating capacity, or to burn more wood to serve the full residential space heating requirement. For the $1 \mathrm{~kW}$ electrical generating capacity, a residential biomass cogeneration system will burn $\sim 1.5 \mathrm{~kg}$ of wood pellets per hour. This projects to $\sim 6.5$ tons of wood pellets per year. (The corresponding amount of fuel wood depends on the moisture content of the fuel.) This amount is similar to the amount burned by homes in Sweden that use pellet furnaces as their primary heat sources

Wood pellets are widely available for retail sale in North America and northern Europe. They are delivered directly to homes throughout Sweden south of the 60th parallel, where more than $80 \%$ of the population lives. Self-cut fuel wood is commonly cut on the homeowner's own woodlot. Purchased fuel wood is delivered by the retail vendor, usually an individual entrepreneur.

\section{Projected System Capital Cost}

Because SMB systems can be targeted at high margin markets where the competing COE is highest, entry prices for these systems can be unusually high. The cost of a competing residential solar photovoltaic electric generator system capable of providing the same $24 \mathrm{kWh} /$ day every day of the year in northern forested territories (where insolation is low) ranges from $\$ 50,000$ to $\$ 100,000$. An international distributor of renewable energy systems believes that the North American remote home market will pay $\$ 10,000$ for 1-kW residential biomass cogeneration systems, i.e., $\$ 10,000 / \mathrm{kW}$.

To open larger markets, prices will need to be reduced, but Sunpower believes this will be achievable as manufacturing volume increases. For sale to on-grid markets, prices may be reduced to $\$ 3,500 / \mathrm{kW}$ or lower. The target high volume system manufacturing cost is $\$ 1,000 / \mathrm{kW}$.

\section{The COE for the Proposed Market}

The economics of the cogeneration of electricity and heat differs fundamentally from those of electric generation, which is critical in enabling residential biomass cogeneration products to compete aggressively against all electric generating technologies. In both electric generation and cogeneration, the COE increases with the system capital cost, the cost of fuel, and the O\&M costs. In cogeneration, however, this cost is reduced by the market value of the heat that is cogenerated and that does not have to be purchased separately from another heat source. Furthermore, the effective cost of cogenerated electricity decreases as the avoided market value of the heat increases. Therefore, the very same cogeneration system produces electricity at different prices, depending on the values of the avoided cost of heat. 
Thus, even at entry market prices for equipment, when it displaces heat from a wood stove, a 1-kW residential biomass cogeneration system in a home in a northern latitude cuts the COE in half. When the competing heat source is a more expensive oil furnace, the reduction in the effective cost of cogenerated electricity is greater, and when the competing heat source is electricity, the reduction is so great that the effective cost of cogenerated electricity actually becomes negative! Furthermore, it becomes most negative where competing electric rates are highest. In France, for example, where the household electric utility rate is $17 \phi / \mathrm{kWh}$, a $1-\mathrm{kW}$ residential biomass cogeneration system sold for $\$ 9,500$ would cogenerate electricity at $-10 \notin / \mathrm{kWh}$ when it displaces heat from an electric heating system. Only through cogeneration can the effective COE be negative.

\section{System Design}

As shown in Figure 8, in the residential biomass cogeneration systems being developed, fuel is first pyrolyzed at $\sim 550^{\circ} \mathrm{C}$ and then mixed with recuperatively preheated secondary air for combustion at $\sim 1400^{\circ} \mathrm{C}$. The resulting exhaust gas is channeled over the head of the free-piston Stirling engine as required by the electrical load, or diverted past the engine to the recuperator. Approximately three-quarters of the heat absorbed by the engine at $550^{\circ} \mathrm{C}$ is rejected into the engine's coolant fluid, which is circulated to the thermal load by an inertia water pump driven by the vibration of the engine body. The rest of the energy absorbed by the engine appears as electric power generated by the linear alternater mechanically linked to the engine's piston.

The combustion exhaust gas leaves the engine at $\sim 700^{\circ} \mathrm{C}$; additional sensible heat is then recuperated into the combustion air to reduce the amount of biomass fuel required to maintain the engine's head temperature. An optional condensing heat exchanger may be employed to recover the latent heat in the exhaust.

The thermal load is composed of parallel loops for domestic hot water, space heating, and system heat rejection. When hot water and space heating loads do not demand all the heat cogenerated with the electrical power, that excess heat must be rejected from the system to the environment.

Several such proof-of-concept prototype systems have been fabricated and their electrical and thermal performances have been confirmed. Further testing is required to determine whether the design requires improvements to reduce cost, increase reliability, and verify compliance with safety and environmental regulations. 


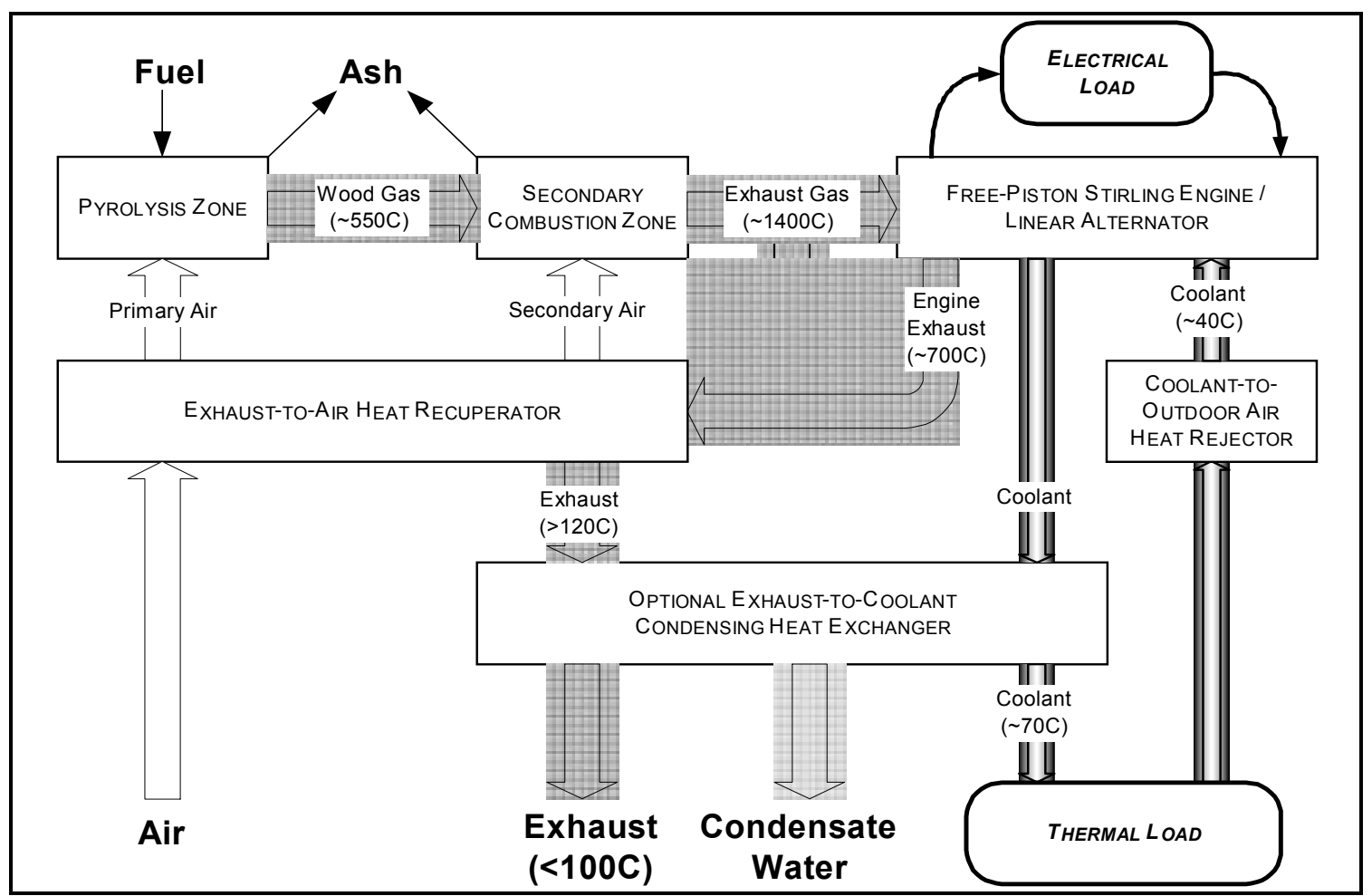

Figure 8.

\section{System Specifications}

On the basis of experience with similar biomass burners and engines, as well as proof-of-concept prototype residential biomass cogeneration systems, the following specifications for the first residential biomass cogeneration system products are forecast:

Size

Dimensions

Electrical Output Power

Thermal Output

Efficiency

Electrical

Thermal

Overall

Reliability

Engine Maintenance

Burner maintenance

Mean Time to Replacement

Environmental emissions

Particulates

$\mathrm{CO}$

$\mathrm{NO}_{\mathrm{x}}$

$\mathrm{SO}_{2}$

Total VOC

$\mathrm{PAH}$
$102.0 \mathrm{~cm} \mathrm{H} \mathrm{x} 76.2 \mathrm{~cm} \mathrm{~W} \mathrm{x} 56.0 \mathrm{~cm} \mathrm{D}$

$1 \mathrm{~kW}$

$3.8 \mathrm{~kW}$ (without supplementary
combustion)

$15 \%$

$68 \%$

$83 \%$

None

Fueling and ash removal

$80,000 \mathrm{~h}$

$<\lg / \mathrm{h}$

$<10$ ppm

$<100$ ppm

nondetectable

$<20 \mathrm{mg} / \mathrm{m}^{3}$ )

$100 \mathrm{mg} / \mathrm{h}$ 


\section{Current Use of this Technology}

The biomass combustion and free-piston Stirling engine technologies in the SMB systems under development are new technologies. Several biomass burners like the ones in proof-of-concept prototypes developed by Sunpower have been fabricated by the original developer and independently tested. Some are in use as residential furnaces and cookstoves. Several dozen free-piston Stirling engines have been fabricated by Sunpower and independently tested. Neither technology has been commercialized in manufactured products.

\section{Technical Issues Resolved during Phase 1}

During Phase 1, system issues concerning the interface of a residential biomass cogeneration unit to residential thermal and electrical loads were resolved. It was decided, for example, to configure domestic water and space heating thermal loads in parallel with the Stirling engine's heat rejection system. It was also decided to size the engine to serve the average annual electrical load rather than the peak and surge loads. A preliminary estimate of manufacturing costs was also made to identify parts and assembly steps on which to focus additional manufacturing engineering to further reduce manufacturing cost.

Under separate internal funding concurrent with Phase 1, Sunpower also fabricated several proof-of-concept residential biomass cogeneration systems. These prototypes confirmed that small biomass combustion systems can be thermally linked to a free-piston Stirling engine, that the engine can respond to changing electrical loads over the full range of its electrical output capacity, and that the heat rejected by the engine can be transferred to a hot water circulation system.

\section{Remaining Technical Issues}

The major technical issues remaining to be resolved relate to manufacturing cost and quality and to the confirmation of expectations about performance and compliance with various safety and environmental regulations. With respect to manufacturing, repeatable, reliable, low-cost manufacturing processes remain to be developed in the factory in which they are to be performed. The performance and compliance of units coming off the factory's production line remain to be confirmed through laboratory tests and field trials.

\section{Environmental Effects of Using or Harvesting Biomass}

Of course, biomass may or may not be harvested in a sustainable manner, and local populations will need to discipline themselves to do so. The raw materials for pellet fuel production would often otherwise make their way into the municipal solid waste system; however, the widespread commercialization of residential biomass cogeneration systems may have a beneficial impact on municipal solid waste streams. Furthermore, if large numbers of homeowners use these products to convert their homes from fossil fuel or electric heating systems, these systems will have beneficial impacts on global warming and acid rain.

\section{Air Emissions}

On the basis of independent measurements of air emissions from a similar two-stage biomass burner fabricated by the original developer, extremely clean emissions performance satisfying the strictest local regulations is expected. The forecast particulate emissions specified are as low as the best pellet and catalytic wood stoves, and the $\mathrm{CO}$ emissions are only $25 \%$ of the gas industry standard for CO-free combustion.

\section{By-Products}

The most economically significant by-product of electrical generation in the SMB systems under development is heat. This cogeneration of heat enables these systems to compete aggressively with other sources of electrical power. In most localities, the ash produced by the planned residential biomass cogeneration systems will be a beneficial soil amendment in homeowners' gardens. One exception is a region in northern Sweden that was contaminated by the Chernoble nuclear accident. The ash from wood harvested in this region is classified as nuclear waste by Swedish authorities, who forbid its disposal by return to the forest. 


\section{Future Development}

\section{Partnerships}

In 1994, Sunpower licensed its free-piston Stirling engine technology to Wood-Mizer Products, Inc. WoodMizer manufactures portable sawmills and distributes them in 104 countries worldwide. In 1996, Wood-Mizer assigned its free-piston Stirling engine rights to External Power, LLC, a new firm created by Wood-Mizer to focus on the commercialization of these engines. External Power plans to manufacture free-piston Stirling engines in various kinds of products. External Power plans to distribute residential biomass cogeneration systems through Wood-Mizer's worldwide network and through other distribution channels.

External Power has also formed a strategic partnership with Energidalen, a biomass energy research center and business incubator in Solleftea, Sweden. Energidalen will perform market analyses for External Power's products in Europe, develop distribution channels, and recruit European investors. Energidalen will also test External Power products to facilitate their approval for sale in the European Union. In addition, Energidalen will make joint proposals with External Power to the European Commission for financial assistance to promote the commercialization of these products throughout the European Union.

To bring residential biomass cogeneration systems to market widely, External Power plans to recruit strategic corporate partners in various industries involved in the biomass energy chain, including forestry, pellet fuels, electric power, residential heating, and white goods.

External Power also plans to recruit other strategic corporate partners and to sell engines to them as original equipment manufacturers for other commercial applications of free-piston Stirling engines. One such application is expected to be natural gas- and propane-fueled residential cogeneration systems.

\section{Sources of Financing for Future Development and Deployment}

External Power plans to finance the development of its first residential biomass cogeneration products and the first factory to produce them by means of a 50\% cost-shared Phase 2 project in the DOE Small Modular Biopower Program. Half the cost of this project will be guaranteed by Wood-Mizer Products, Inc. Subsequently, External Power will seek to finance widespread field trials of these products in North America and Europe by means of a Phase 3 project in the same program, with cost equally shared by External Power, DOE, and the European Commission. Financing for the startup and expansion of full-scale production, distribution, sales, and service will be sought from banks, strategic corporate partners, venture capitalists, and private and public offerings of stock, as well as from retained earnings on early sales in high margin markets.

\section{Marketing and Original Equipment Strategy}

External Power is still developing its marketing and distribution strategy, but expects to distribute residential biomass cogeneration systems to homeowners through various distribution channels, including Wood-Mizer's worldwide distribution network, pellet fuel distributors, heating equipment distributors, and electric utilities as well as through direct sales via electronic commerce. Where appropriate, External Power also plans to sell free-piston Stirling engines to original equipment manufacturers for inclusion in cogeneration and electrical generation systems sold under their labels and brand names. 
Market Entry and Growth Strategy

Directly and through strategic partners, External Power plans to offer residential biomass cogeneration products first to the off-grid market in the forested territories of northern North America where the competing COE is very high. In this region homes have a substantial thermal load and homeowners are accustomed to burning wood for heat. External Power then plans to expand sales to northern Europe where similar conditions prevail, except that few homes are off-grid; however, the competing COE from electric utilities is much higher than in North America. Only later will External Power attempt to enter on-grid markets in North America, probably first in the Northeastern States and in high-cost rural load pockets of electric utilities elsewhere.

External Power products will be marketed first to homeowners who are already accustomed to burning wood for heat, and later to homeowners who wish to glean the large economic and environmental benefits of converting their homes from oil and electric to biomass heat sources.

In parallel, External Power will distribute residential biomass cogeneration systems in developing countries through Wood-Mizer's worldwide network of distributors. Through other strategic partners, External Power will expand operations in these countries as their markets mature.

As other biomass fuels become commercially available for residential use, External Power will develop new products to burn those fuels. Possible future commercial biofuels include herbaceous crops and wastes, biodiesel oil, and ethanol.

Finally, External Power also plans to develop products with electrical capacities as high as $20 \mathrm{~kW}$ or more for larger residential, small commercial, and agricultural markets. 


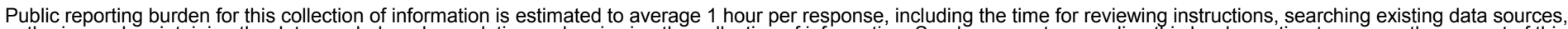

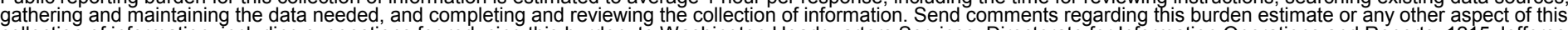

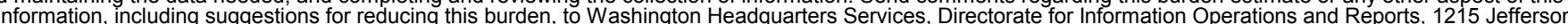

Davis Highway, Suite 1204, Arlington, VA 22202-4302, and to the Office of Management and Budget, Paperwork Reduction Project (0704-0188), Washington, DC 20503.

\begin{tabular}{|l|l|l|} 
1. AGENCY USE ONLY (Leave blank) & $\begin{array}{c}\text { 2. REPORT DATE } \\
\text { February } 2000\end{array}$ & $\begin{array}{l}\text { 3. REPORT TYPE AND DATES COVERED } \\
\text { Technical Report }\end{array}$ \\
\hline
\end{tabular}

\section{TITLE AND SUBTITLE}

5. FUNDING NUMBERS

Small Modular Biopower Initiative Phase I Feasibility Studies Executive Summaries

BP001040

\section{AUTHOR(S)}

R. Bain

7. PERFORMING ORGANIZATION NAME(S) AND ADDRESS(ES)

8. PERFORMING ORGANIZATION REPORT NUMBER

\section{SPONSORING/MONITORING AGENCY NAME(S) AND ADDRESS(ES)}

National Renewable Energy Laboratory

1617 Cole Boulevard

Sandia National Laboratory, New Mexico

Golden, CO 80401-3393

10. SPONSORING/MONITORING AGENCY REPORT NUMBER

NREL/TP-570-27592

\section{SUPPLEMENTARY NOTES}

12a. DISTRIBUTION/AVAILABILITY STATEMENT

National Technical Information Service

U.S. Department of Commerce

5285 Port Royal Road

Springfield, VA 22161

13. ABSTRACT (Maximum 200 words) The Phase I objective is a feasibility study that includes a market assessment, resource assessment, preliminary system design, and assessment of relevant environmental and safety considerations, and evaluation of financial and cost issues, and a preliminary business plan and commercialization strategy. Each participating company will share at least $20 \%$ of the cost of the first phase.

\section{SUBJECT TERMS}

small modular biomass power systems, fuel flexibility, resource assessment, system fuel consumption

17. SECURITY CLASSIFICATION OF REPORT

Unclassified 12b. DISTRIBUTION CODE

18. SECURITY CLASSIFICATION
OF THIS PAGE
OF THIS PAGE Unclassified

\section{SECURITY CLASSIFICATION OF ABSTRACT Unclassified}

\section{NUMBER OF PAGES}

16. PRICE CODE

20. LIMITATION OF ABSTRACT $\mathrm{UL}$ 